\title{
Chlorpromazine Inhibits Miniature GABAergic Currents by Reducing the Binding and by Increasing the Unbinding Rate of $\mathrm{GABA}_{\mathrm{A}}$ Receptors
}

\author{
Jerzy W. Mozrzymas, ${ }^{1,2}$ Andrea Barberis, ${ }^{1}$ Krystyna Michalak, ${ }^{2}$ and Enrico Cherubini ${ }^{1}$ \\ ${ }^{1}$ Neuroscience Program and Istituto Nazionale Fisica della Materia Unit, International School for Advanced Studies, \\ 34014 Trieste, Italy, and 2Department of Biophysics, Wroclaw University of Medicine, 50368 Wroclaw, Poland
}

Recent studies have emphasized that nonequilibrium conditions of postsynaptic $\mathrm{GABA}_{A}$ receptor $\left(G A B A_{A} R\right)$ activation is a key factor in shaping the time course of IPSCs (Puia et al., 1994; Jones and Westbrook, 1995). Such nonequilibrium, resulting from extremely fast agonist time course, may affect the interaction between pharmacological agents and postsynaptic $\mathrm{GABA}_{A}$ Rs. In the present study we found that chlorpromazine (CPZ), a widely used antipsychotic drug known to interfere with several ligand and voltage-gated channels, reduces the amplitude and accelerates the decay of miniature IPSCs (mIPSCs). A good qualitative reproduction of the effects of CPZ on mIPSCs was obtained when mIPSCs were mimicked by responses to ultrafast GABA applications to excised patches. Our experimental data and model simulations indicate that CPZ affects mIPSCs by decreasing the binding $\left(k_{\text {on }}\right)$ and by increasing the

Phenothiazines (PTZs) are a family of compounds commonly used in the treatment of psychiatric disorders. The mechanism whereby these drugs exert their therapeutic effects appears to be through blockade of dopamine receptors (Snyder et al., 1974; Seeman, 1980). However, these substances have been shown to affect also a number of other physiologically important sites. It is known, for instance, that PTZs compete for serotonin and $\alpha$-adrenergic and histamine receptors (Peroutka and Snyder, 1980). More recently, electrophysiological studies have shown that PTZs interfere with a number of ligand- and voltageactivated channels (Gould et al., 1983; Sand et al., 1983; Changeux et al., 1986; Dinan et al., 1987; Zorumski and Yang, 1988; Ogata et al., 1989; Müller et al., 1991; Bolotina et al., 1992; Benoit and Changeux, 1993; Lidsky et al., 1997). In particular, it has been reported that PTZs block in a noncompetitive manner the responses evoked by exogenous application of GABA (Zorumski and Yang, 1988) and reduce the amplitude of IPSCs (Agopyan and Krnjevic, 1993), but the mechanism of these effects has not been elucidated. It is likely that the noncompetitive block of $\mathrm{GABA}_{\mathrm{A}}$ receptors by PTZs, reported by Zorumski and Yang

Received Oct. 19, 1998; revised Jan. 11, 1999; accepted Jan. 19, 1999.

This work was supported by a grant from Ministero dell'Università e Ricerca Scientifica e Tecnologica and from Consiglio Nazionale delle Ricerche. J.W.M. and K.M. were supported by Polish Committee for Scientific Research, research funds for Wroclaw University of Medicine. A.B. was supported by a fellowship from Novartis Pharmaceuticals. The Bioq software with which the kinetic modelling was performed was kindly provided by Dr. H. Parnas from the Hebrew University (Jerusalem).

Correspondence should be addressed to Enrico Cherubini, International School for Advanced Studies, via Beirut 2-4, 34014 Trieste, Italy.

Copyright (C) 1999 Society for Neuroscience $0270-6474 / 99 / 192474-15 \$ 05.00 / 0$ unbinding $\left(k_{\text {off }}\right)$ rates of GABA $\mathrm{A}$ s. Because of reduction of $k_{\text {on }}$ by $C P Z$, the binding reaction becomes rate-limiting, and agonist exposure of GABA $_{A}$ Rs during mIPSC is too short to activate the receptors to the same extent as in control conditions. The increase in unbinding rate is implicated as the mechanism underlying the acceleration of mIPSC decaying phase. The effect of $C P Z$ on $G_{A B A} R$ binding rate, resulting in slower onset of GABA-evoked currents, provides a tool to estimate the speed of synaptic clearance of GABA. Moreover, the onset kinetics of recorded responses allowed the estimate the peak synaptic GABA concentration.

Key words: chlorpromazine; $G A B A_{A}$ receptors; miniature IPSCs; patch-clamp; binding and unbinding rate constants; hippocampus
(1988), is one of the processes underlying the reduction in amplitude of IPSCs observed by Agopyan and Krnjevic (1993). However, in the experiments of Zorumski and Yang (1988), GABA application system was too slow to mimic the time course of the agonist in the synapse, making it difficult to directly refer these results to the PTZs effects on synaptic currents.

A downregulation of synaptic inhibition may play an important role in the induction of epileptic activity. Thus, a further understanding of the effects of PTZ on inhibitory synaptic transmission appears to be particularly important because the use of PTZs may be associated (especially at high doses) with adverse effects, including seizures (Toone and Fenton, 1977; Itil and Soldatos, 1980).

The aim of the present work was to study the mechanisms underlying the effects of chlorpromazine (CPZ), a widely used PTZ, on miniature IPSCs (mIPSCs) in cultured hippocampal neurons. We report that $C P Z$ reduces the amplitude of mIPSCs in a dose-dependent manner and accelerates their decay. The mechanism of $\mathrm{CPZ}$ action on $\mathrm{GABA}_{\mathrm{A}}$ receptors was studied using the ultrafast GABA applications to excised patches that fairly mimicked the synaptic currents. The results have been expressed in terms of a kinetic model, and it is suggested that the effects of $\mathrm{CPZ}$ are caused by a reduction in binding and increase in unbinding rates of $\mathrm{GABA}_{\mathrm{A}}$ receptor channel.

\section{MATERIALS AND METHODS}

Cell culture. Primary cell culture was prepared as described previously (Andjus et al., 1997). Briefly, hippocampi were dissected from 2- to 
4-d-old rats, sliced and digested with trypsin, mechanically triturated, centrifuged twice at $40 \times g$, plated in the Petri dishes, and cultured for up to $12 \mathrm{~d}$. Experiments were performed on cells between 5 and $12 \mathrm{~d}$ in culture.

Electrophysiological recordings. Currents were recorded in the wholecell and outside-out configurations of the patch-clamp technique using the EPC-7 amplifier (List Medical, Darmstadt, Germany). In the case of whole-cell recordings of the synaptic and GABA-evoked currents, the series resistance $\left(R_{\mathrm{s}}\right)$ was in the range of $4-8 \mathrm{M} \Omega$, and $50-70 \%$ of $R_{\mathrm{s}}$ compensation was accomplished. Both mIPSCs and GABA-elicited currents in the excised patch configuration were recorded at a holding potential $\left(V_{\mathrm{h}}\right)$ of $-70 \mathrm{mV}$. In the whole-cell configuration, GABAevoked responses were often very large $(>1 \mathrm{nA})$. To diminish a possible distortion caused by $R_{\mathrm{s}}$, the electrical driving force for chloride ions was reduced by setting the $V_{\mathrm{h}}$ at $-30 \mathrm{mV}$. The intrapipette solution contained (in mM) $\mathrm{CsCl} 137, \mathrm{CaCl}_{2} 1, \mathrm{MgCl}_{2}$ 2, 1,2-bis(2-aminophenoxy)ethane$N, N, N^{\prime}, N^{\prime}$-tetra-acetic acid (BAPTA) 11, ATP 2, and HEPES 10, pH 7.2 with $\mathrm{CsOH}$. The composition of the external solution was (in $\mathrm{mM}$ ) $\mathrm{NaCl}$ 137, $\mathrm{KCl} 5, \mathrm{CaCl}_{2} 2, \mathrm{MgCl}_{2} 1$, glucose 20, and HEPES 10, pH 7.4 with $\mathrm{NaOH}$. mIPSCs were recorded in the presence of tetrodotoxin (TTX; 1 $\mu \mathrm{M})$ and kynurenic acid $(1 \mathrm{~mm})$ to block fast sodium spikes and glutamatergic EPSCs. All the experiments were performed at room temperature $22-24^{\circ} \mathrm{C}$.

The current signals were stored on a video recorder after pulse-code modulation. For the analysis requiring a high temporal resolution (e.g., rise time kinetics of synaptic or evoked currents), the signals were low-pass filtered at $10 \mathrm{kHz}$ with a Butterworth filter and sampled at $50-100 \mathrm{kHz}$ using the analog-to-digital converter CED 1401 (Cambridge Electronic Design Limited, Cambridge, UK) and stored on the computer hard disk. Otherwise, for analysis of slower events, the cutoff frequency of the filter and the sampling rate were lowered accordingly. The data and acquisition software were kindly given by Dr. J. Dempster (Strathclyde University, Glasgow, UK).

Two different perfusion systems for GABA applications were used: the multibarrel RSC-200 perfusion system (Bio-Logic, Grenoble, France) and the ultrafast system based on the use of a piezoelectric-driven theta glass application pipette (Jonas, 1995). The head of the multibarrel system was modified to improve the speed of drug application on cells adhering to the bottom of Petri dishes. This system was used either to evoke the whole-cell GABA-induced currents or to exchange the solution around the cell from which the synaptic activity was recorded. Judging from the onset of the liquid junction potentials, a complete exchange of the solution around the open-tip electrode occurred within 10-20 msec. A better indication of the exchange time around the cell was given by the rise time of whole-cell responses evoked by high concentrations of GABA $(>1 \mathrm{~mm})$. Because it is known that with those concentrations the rise time of GABA responses is less than or close to $1 \mathrm{msec}$ (Maconochie et al., 1994; see also Results and Discussion), the observed rate of rise of the whole-cell current $(15-30 \mathrm{msec})$ was mainly determined by the speed of the solution exchange. The piezoelectric translator used for ultrafast perfusion system was from Physik Instrumente (Waldbronn, Germany), and theta glass tubing was from Hilgenberg (Malsfeld, Germany). For this perfusion system, the open-tip recordings of the liquid junction potentials revealed that complete exchange of solution occurred within $80-250 \mu \mathrm{sec}$.

When studying the effect of CPZ on GABA-evoked currents, GABA was applied in the presence of $C P Z$, after pre-equilibration at the same $\mathrm{CPZ}$ concentration for at least $4 \mathrm{~min}$.

Analysis. The decaying phase of the currents was fitted with a biexponential function in the form:

$$
y(t)=A_{\text {fast }} \exp \left(-t / \tau_{\text {fast }}\right)+A_{\text {slow }} \exp \left(-t / \tau_{\text {slow }}\right)+A_{\mathrm{s}}
$$

where $A_{\text {fast }}, A_{\text {slow }}$ are the fraction of the fast and slow component, respectively, $A_{\mathrm{s}}$ is the steady-state current, and $\tau_{\text {fast }}$ and $\tau_{\text {slow }}$ are the fast and the slow time constants. In the case of analysis of normalized currents, the fractions of kinetic components fulfilled the normalization condition: $A_{\text {fast }}+A_{\text {slow }}+A_{\mathrm{s}}=1$. When fitting the IPSCs or deactivation currents, the steady-state component $A_{\mathrm{s}}$ was omitted.
To compare the time duration of the agonist presence in the case of different patterns of concentration time course, the effective exposure $E$ was defined as following:

$$
E=\int_{0}^{\infty} c(t) d t,
$$

where $c(t)$ is the concentration and $t=$ time. In the case of the square-like (with amplitude $A$ and time of application $t_{\text {appl }}$ ) and exponential time course $(A \cdot \exp (-t / \tau))$ the effective exposure would be: $A \cdot t_{\text {appl }}$ and $A \cdot \tau$, respectively.

The kinetic modelling was performed with the Bioq software kindly provided by Dr. H. Parnas from the Hebrew University, Jerusalem. The Bioq software converted the kinetic model (Fig. 8) into a set of differential equations and solved them numerically assuming, as the initial condition, that at $t=0$, no bound or open receptors were present. Various experimental protocols were investigated by "clamping" the agonist concentration time course in the form of square-like pulses (ultrafast perfusion experiments) or of an exponentially decaying function (to model the synaptic clearance). The solution of such equations yielded the time courses of probabilities of all the states assumed in the model. The fit to the experimental data were performed by optimizing the values of rate constants for a given experimental protocol.

Data are expressed as mean \pm SEM. Student's unpaired $t$ test was used for comparison of data.

\section{RESULTS}

\section{CPZ reduces the amplitude of mIPSCs}

mIPSCs were recorded in the whole-cell configuration of the patch-clamp technique, at a holding potential of $-70 \mathrm{mV}$, in the presence of TTX $(1 \mu \mathrm{M})$ and kynurenic acid $(1 \mathrm{~mm})$ in 9 of 15 cells. mIPSCs were GABA $_{\mathrm{A}}$-mediated because they were reversibly blocked by bicuculline (10 $\mu \mathrm{M}$, data not shown). mIPSCs had a mean amplitude of $-77.2 \pm 15 \mathrm{pA}(n=9)$. CPZ applied in the bath at concentrations of 10-100 $\mu \mathrm{M}$ induced a dose-dependent decrease in mIPSC amplitude (Fig. $1 A, B$ ). As shown in the graph of Figure $1 E$, in the presence of 10,30 , and $100 \mu \mathrm{M} \mathrm{CPZ}$, the synaptic currents were decreased to $0.74 \pm 0.1,0.69 \pm 0.12$, and $0.09 \pm 0.07(n=5)$ of the control value, respectively.

\section{CPZ accelerates the decay of mIPSCs}

The effectiveness of synaptic inhibition does not depend only on the amplitude but also on the time course of synaptic currents. Especially in the case of IPSC, the decay kinetics is particularly important for temporal integration of synaptic signals as the decaying phase of IPSCs are known to be long lasting, often exceeding hundreds of milliseconds (Edwards et al., 1990; Pearce, 1993; Puia et al., 1994; Jones and Westbrook, 1995).

Similar to previous reports (Edwards et al., 1990; Jones and Westbrook, 1995), the decay of mIPSCs recorded in our experiments could be well fitted with the sum of two exponentials (Fig. $1 A$, Table 1). To compare the decay kinetics in control conditions and in the presence of $\mathrm{CPZ}$, the synaptic events were averaged, and the traces were fitted with theoretical curves (Fig. 1A,B). When superimposing the normalized traces (Fig. 1C), a clear acceleration of the decaying phase in the presence of $30 \mu \mathrm{M} \mathrm{CPZ}$ is evident. This effect was dose-dependent, being negligible at 10 $\mu \mathrm{M}$, but gradually increased at higher CPZ concentrations (Table 1). The acceleration of mIPSC decay by CPZ was a consequence of a decrease in the area and in the time constant of the slower component (Table 1). Thus, a decreased amplitude and accelerated decay of mIPSCs are the two factors whereby $\mathrm{CPZ}$ reduces the charge transfer associated with a single mIPSC (charge transfer calculated as the integral of mIPSC). As shown in Figure $1 E$, 
A

Control

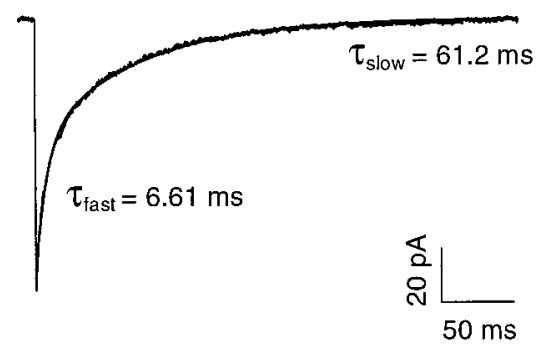

C

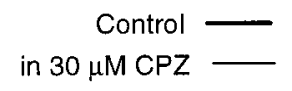

Figure 1. CPZ decreases the amplitude and accelerates the decay of mIPSCs. $A$, Average of $57 \mathrm{mIPSCs}$ recorded from the same cell $\left(V_{\mathrm{h}}=-70 \mathrm{mV}\right)$. The decaying phase of the trace was fitted with Equation 1 (Materials and Methods), assuming $A_{\mathrm{s}}=0$. The values of time constants are specified below the trace. $B$, Average of $76 \mathrm{mIPSCs}$ recorded in the presence of $30 \mu \mathrm{M} \mathrm{CPZ} \mathrm{(from} \mathrm{the}$ same cell as in $A$ ). Traces were fitted with Equation 1. $C$, Superimposed, normalized current records shown in $A$ (thick line) and $B$ (thin line). A clear acceleration of the decaying phase in the presence of $30 \mu \mathrm{M} \mathrm{CPZ}$ is evident. $D$, The normalized traces shown in $C$ are presented in an expanded time scale. Note that CPZ had no effect on the onset of mIPSC. $E$, Dose dependence of the effect of CPZ on mIPSC amplitude (open columns) and area (hatched columns). Amplitudes and areas were normalized (dotted line) to the control values. The CPZ concentrations are indicated above the bars. In this and in the following figures, bars above the columns represent SEM.

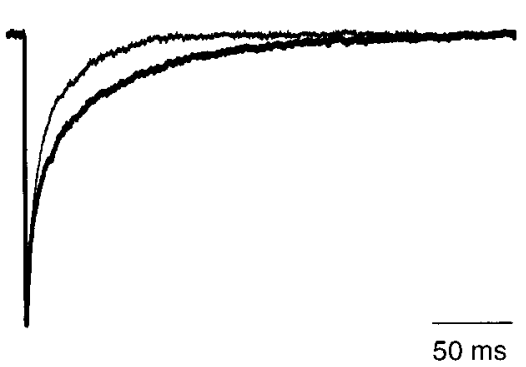

B

in $30 \mu \mathrm{M} \mathrm{CPZ}$

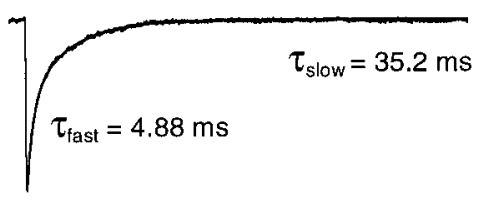

叴
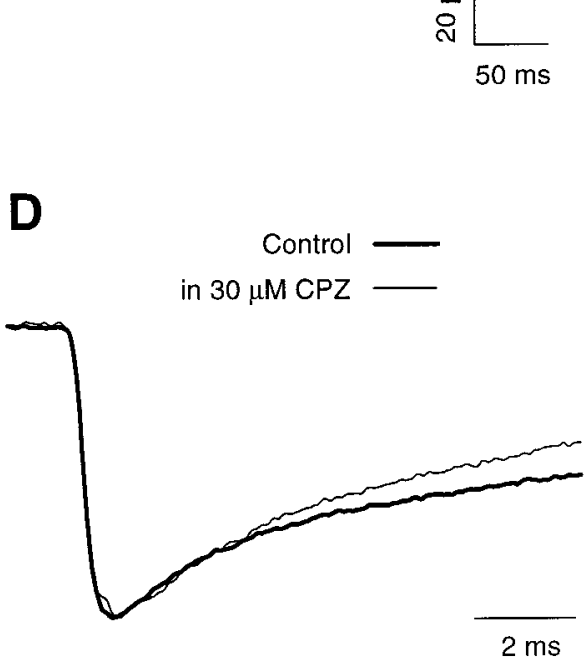

$2 \mathrm{~ms}$

Table 1. Kinetic analysis of normalized mIPSCs

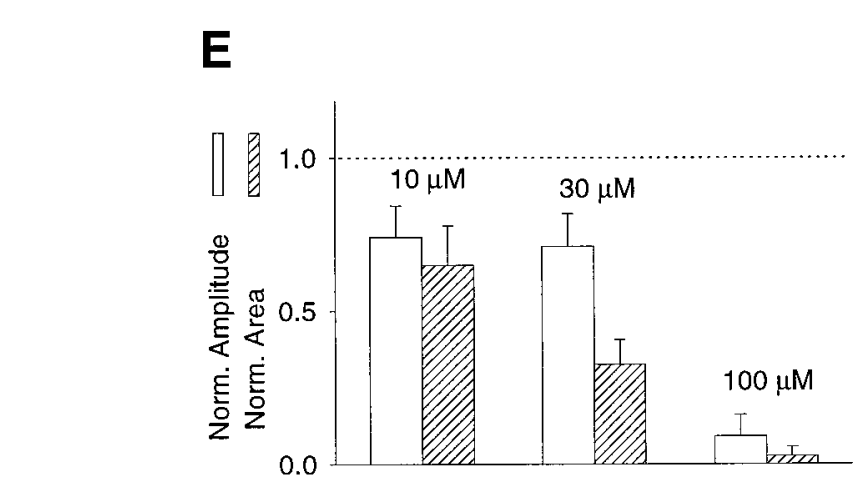

\begin{tabular}{lllcc} 
& & $\mathrm{CPZ}$ & $30 \mu \mathrm{M}$ & \\
\cline { 3 - 5 } Constant & Control & $10 \mu \mathrm{M}$ & $7.1 \pm 0.8$ & $100 \mu \mathrm{M}$ \\
\hline$\tau_{\text {fast }}(\mathrm{msec})$ & $10.9 \pm 2.2$ & $14.5 \pm 2.1$ & $0.67 \pm 0.04$ & $5.2 \pm 1.1^{*}$ \\
$\mathrm{~A}_{\text {fast }}$ & $0.60 \pm 0.06$ & $0.62 \pm 0.08$ & $27.2 \pm 5.8^{*}$ & $1.0^{*}$ \\
$\tau_{\text {slow }}(\mathrm{msec})$ & $60.3 \pm 6.7$ & $79 \pm 15.1$ & $0.66 \pm 0.04$ & $0.73 \pm 0.05$ \\
Rise time (msec) & $0.68 \pm 0.09$ & $0.82 \pm 0.12$ &
\end{tabular}

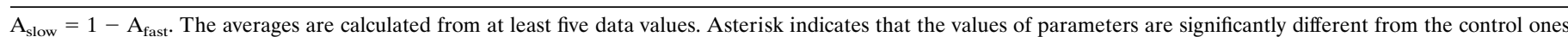
$(p<0.05)$.

the CPZ-induced increase in the decay rate of mIPSCs contributes substantially to the decrease in the mIPSC area (charge transfer), especially at higher $(\geq 30 \mu \mathrm{M})$ concentrations of CPZ.

We have also examined whether $\mathrm{CPZ}$ affects the rise time of mIPSCs. We found that in control conditions and in the presence of CPZ $(10-100 \mu \mathrm{M})$ the $10-90 \%$ rise time was not significantly $(p>0.5)$ different (Fig. 1D, Table 1).

\section{CPZ affects whole-cell GABA-induced currents}

To further explore the mechanisms underlying CPZ-induced decrease in the amplitude and acceleration of mIPSC decay kinetics, the effect of this drug was studied on the whole-cell currents evoked by applications of GABA from a multibarrel perfusion system (see Materials and Methods). These experi- 
A

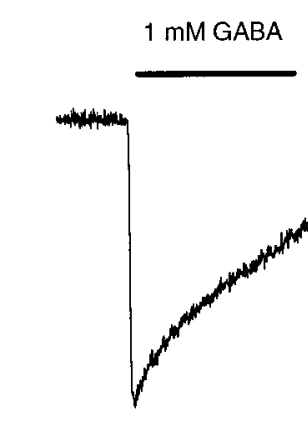

Control

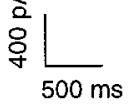

C

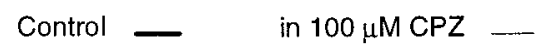

$1 \mathrm{mM}$ GABA

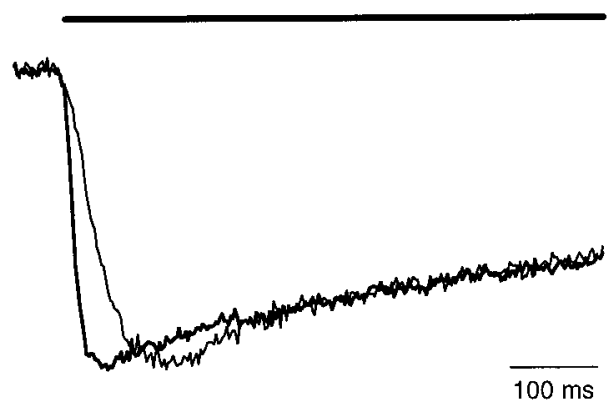

B in $100 \mu \mathrm{M} \mathrm{CPZ}$

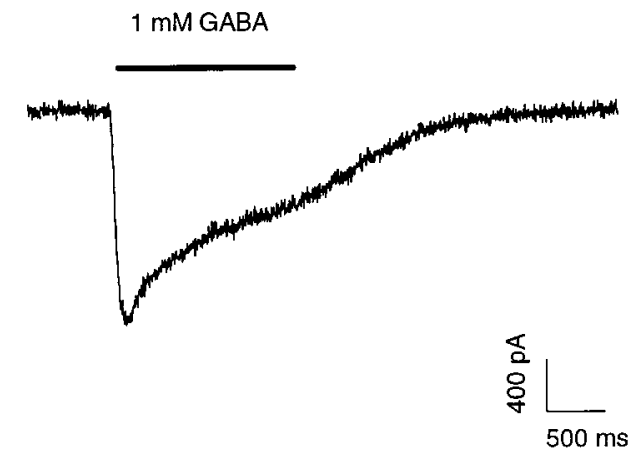

D

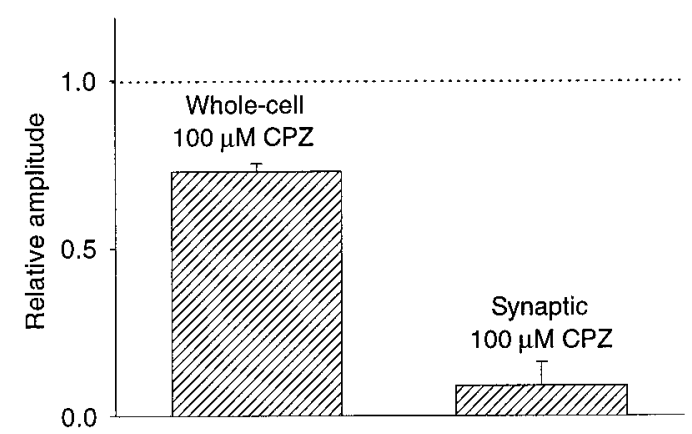

Figure 2. CPZ affects the whole-cell currents evoked by GABA using the multibarrel perfusion system. $A, B$, Example of whole-cell currents evoked by GABA $(1 \mathrm{~mm}$, bars $)$ in control $(A)$ and in the presence of $100 \mu \mathrm{M} \mathrm{CPZ}(B)$ at $V_{\mathrm{h}}=-30 \mathrm{mV}$. $C$, Same traces as in $A$ (thick line) and $B($ thin line) are normalized and superimposed. Note the slower rate of current onset in the presence of CPZ. $D, \mathrm{CPZ}$ affects the amplitude of the whole-cell GABA-evoked currents to a much smaller extent than that of mIPSCs ( 0.73 vs 0.09 of the control values, respectively).

ments were performed on the same neurons from which mIPSCs were recorded. The rise time of the whole-cell current induced by high doses of GABA ( $\geq 1 \mathrm{~mm}$ ) was in the range of 15-30 msec. Figure $2 A$ shows a typical example of the current evoked by GABA (1 mM, applied for $1.2 \mathrm{sec}$ ) at a holding potential of -30 $\mathrm{mV}$. Application of the same GABA concentration in the presence of $100 \mu \mathrm{M} \mathrm{CPZ}$ led to a significant decrease in the amplitude and in the onset rate of GABA-evoked current (Fig. 2B,C). On average, the amplitude of GABA-induced currents in the presence of CPZ $(100 \mu \mathrm{M})$ was $0.73 \pm 0.03$ of the control value (Fig. $2 D)$. This effect was independent of GABA concentration in the range from 5 to $1000 \mu \mathrm{M}$, suggesting a noncompetitive type of block. The most striking discrepancy between the effect of CPZ on mIPSCs and on the currents evoked by exogenous GABA application was the amount of their block by CPZ. As shown in Figure $2 D$, whereas $100 \mu \mathrm{M} \mathrm{CPZ}$ reduced the mIPSCs amplitude by $\sim 90 \%$, the same CPZ concentration induced only $\sim 30 \%$ depression of GABA-evoked responses. CPZ $(100 \mu \mathrm{M})$ increased also the time-to-peak of GABA-evoked $(1 \mathrm{~mm})$ current from $21 \pm$ 3.4 to $54 \pm 7.4 \mathrm{msec}$ (Fig. $3 C ; n=3$ ). However, it is known that when GABA (1 mM) is applied with a fast perfusion system (Maconochie et al., 1994; Puia et al., 1994), the time-to-peak is close or $<1 \mathrm{msec}$. This indicates that the rise time observed in our experiments reflects mainly the speed of drug application. The estimated rise time of the agonist concentration in the synaptic cleft (Clements, 1996) is at least two orders of magnitude faster than that obtained by our perfusion system. It is thus likely that the interaction of CPZ with mIPSCs occurs at a much faster time scale and for this reason cannot be reproduced by a conventional perfusion system. To test this possibility, a series of experiments was performed using an ultrafast perfusion system.

\section{GABA applied by a ultrafast perfusion system mimics synaptic currents}

The open-tip recordings of the liquid junction potentials showed that using the ultrafast perfusion system (see Materials and Methods), a complete exchange of solution occurred within $80-$ $250 \mu \mathrm{sec}$. These values are similar to those reported by Jonas (1995) and Maconochie et al. (1994). Figure $3 A$ shows a typical current response to $1 \mathrm{~mm}$ GABA applied for $2 \mathrm{msec}$ to an excised patch at a holding potential of $-70 \mathrm{mV}$. Similar to what observed for mIPSCs, the currents were characterized by a biphasic decay described by two time constants (Table 2). The fast decay time constant $\left(\tau_{\text {fast }}\right)$ of mIPSCs and of GABA responses was not significantly different ( $p>0.3$; Tables 1,2$)$. However, the time constant of the slower component $\left(\tau_{\text {slow }}\right)$ was significantly longer $(p<0.05)$ in the case of currents evoked by fast GABA applications. The latter finding is similar to the observation of Jones 
A Fast perfusion (1 mM GABA, 2 ms)

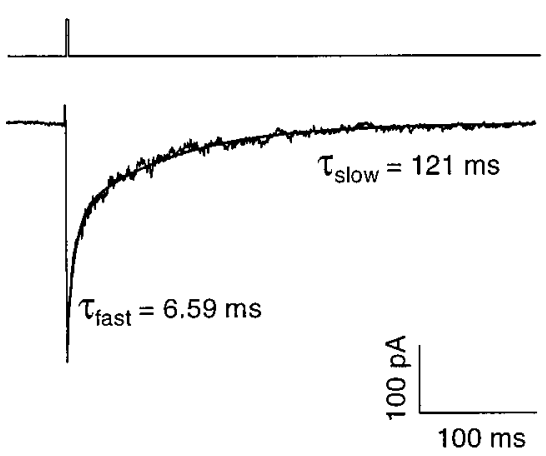

C
B Synaptic
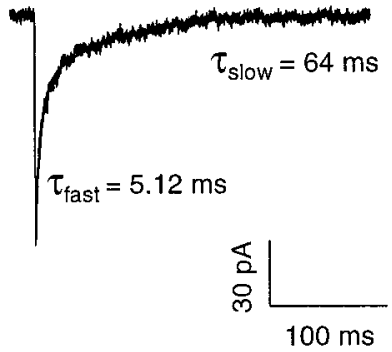

Figure 3. Currents evoked by brief GABA applications, using the fast perfusion system, mimic mIPSCs. $A$, Example of current evoked by brief GABA application (1 $\mathrm{mm}$ for $2 \mathrm{msec}$, see inset above the current trace). The decaying phase of GABA-evoked current was fitted with Equation 1 (Materials and Methods), assuming $A_{\mathrm{s}}=0$; the values of time constants are specified below the trace. $B$, Example of a mIPSC with a biexponential curve fitting (Eq. 1, $A_{\mathrm{s}}=0$ ) to the decaying phase. $C$, Example of the rising phases of currents evoked by different GABA concentrations. The duration of GABA application was long enough to reach the peak current value. The rising kinetics saturates at $\sim 3$ mM GABA.

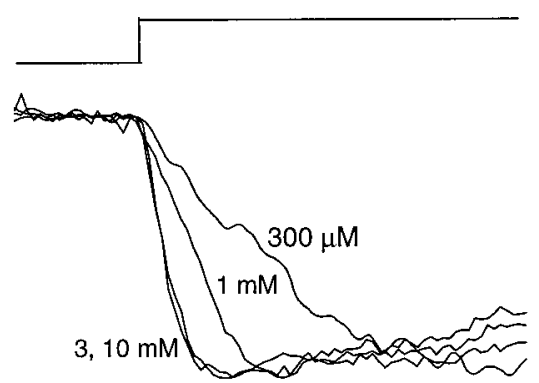

$1 \mathrm{~ms}$

Table 2. Kinetics of normalized GABA-evoked current using fast perfusion (application time, 2 msec)

\begin{tabular}{|c|c|c|c|c|c|}
\hline \multirow[b]{2}{*}{ Constant } & \multicolumn{3}{|l|}{$1 \mathrm{~mm}$ GABA } & \multicolumn{2}{|c|}{$10 \mathrm{~mm}$ GABA } \\
\hline & Control & $30 \mu \mathrm{M} \mathrm{CPZ}$ & $100 \mu \mathrm{M} \mathrm{CPZ}$ & Control & $100 \mu \mathrm{M} \mathrm{CPZ}$ \\
\hline$\tau_{\text {fast }}(\mathrm{msec})$ & $8.7 \pm 1.4$ & $9.7 \pm 1.0$ & $6.2 \pm 0.5$ & $4.9 \pm 0.4$ & $6.4 \pm 0.6$ \\
\hline $\mathrm{A}_{\text {fast }}$ & $0.62 \pm 0.02$ & $0.65 \pm 0.02$ & $0.82 \pm 0.02 *$ & $0.51 \pm 0.02$ & $0.85 \pm 0.02 *$ \\
\hline$\tau_{\text {slow }}(\mathrm{msec})$ & $123.5 \pm 12$ & $133 \pm 13$ & $139 \pm 22$ & $104 \pm 9$ & $114 \pm 12$ \\
\hline Rise time (msec) & $1.12 \pm 0.08$ & $1.61 \pm 0.19^{*}$ & $1.82 \pm 0.06^{*}$ & $0.76 \pm 0.05$ & $0.81 \pm 0.06$ \\
\hline
\end{tabular}

$\mathrm{A}_{\text {slow }}=1-\mathrm{A}_{\text {fast }}$. The averages are calculated from at least 10 data values. Asterisk indicates that the values of parameters are significantly different from the control ones $(p<0.05)$.

and Westbrook (1995) who also found that the decay of GABA responses is slower than that of the synaptic currents. The rate of the rising phase was dependent on GABA concentration and similar to what was observed by Jones and Westbrook (1995), saturated at $\sim 3 \mathrm{~mm}$ GABA (Fig. $3 C$ ). Thus, the above analysis shows that currents evoked by fast GABA applications reproduce qualitatively the major kinetic properties of mIPSCs. Taking this into account, such GABA responses were used as a tool to explore the mechanism of the effect of $\mathrm{CPZ}$ on the kinetics of mIPSCs.

The currents elicited by fast GABA applications (1 mM GABA for $2 \mathrm{msec}$ ) were also recorded in the presence of CPZ. Figure $4 A$ shows typical responses to fast GABA applications in control conditions in the presence of 30 and $100 \mu \mathrm{M}$ CPZ. On average, CPZ (30 and $100 \mu \mathrm{M}$ ) reduced the current amplitude to $0.71 \pm$ $0.15(n=10)$ and $0.32 \pm 0.09(n=17)$ of the control values (Fig. $4 C$ ), respectively. As shown in Figure $4 C$, the percentage of the amplitude reduction by $30 \mu \mathrm{M} \mathrm{CPZ}$ was very similar to that observed for mIPSCs but with $100 \mu \mathrm{M} \mathrm{CPZ}$, the reduction of the current was smaller. However, with respect to the block of $\mathrm{mIP}$ SCs by CPZ, a much better agreement was obtained when mIPSCs were modelled by current responses evoked by fast GABA applications rather than by slower multibarrel perfusion (compare Figs. $2 D, 4 D$ ). This observation indicates that indeed the effect of $\mathrm{CPZ}$ on $\mathrm{GABA}_{\mathrm{A}}$ receptors strongly depends both on speed and time duration of agonist application.

$\mathrm{CPZ}$ affected also the decay of currents evoked by fast GABA pulses. At 10 and $30 \mu \mathrm{M} \mathrm{CPZ}$, the effect was negligible, but at 100 $\mu \mathrm{M}$ a clear acceleration of the decay kinetics was observed (Fig. $4 B$, Table 2) reproducing qualitatively the effect of $\mathrm{CPZ}$ on the mIPSC decaying phase.

What is the mechanism whereby $\mathrm{CPZ}$ affects so strongly mIPSCs and currents evoked by fast GABA applications? A hint to understand this problem came from the analysis of the effect of $\mathrm{CPZ}$ on rise time of currents evoked by brief pulses of GABA. As shown in Figure $5 A$, the onset of the current evoked by GABA (1 $\mathrm{mM}$ ) in the presence of $100 \mu \mathrm{M} \mathrm{CPZ}$ was clearly slower than in control. On average, in control conditions, the $10-90 \%$ rise time 
A

Control

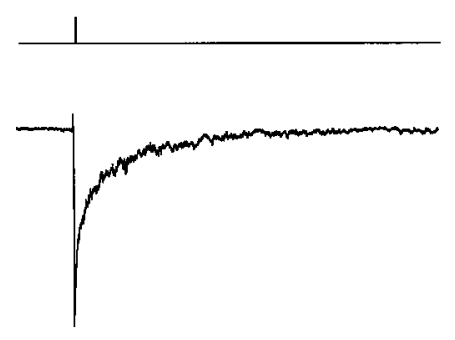

in $30 \mu \mathrm{M} \mathrm{CPZ}$

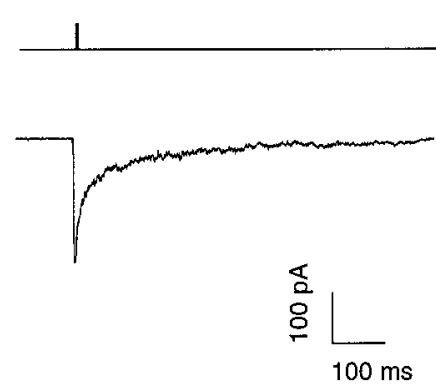

in $100 \mu \mathrm{M} \mathrm{CPZ}$
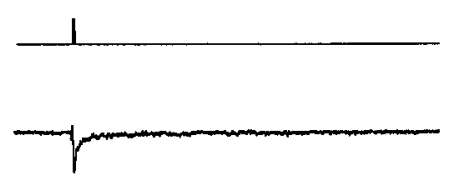
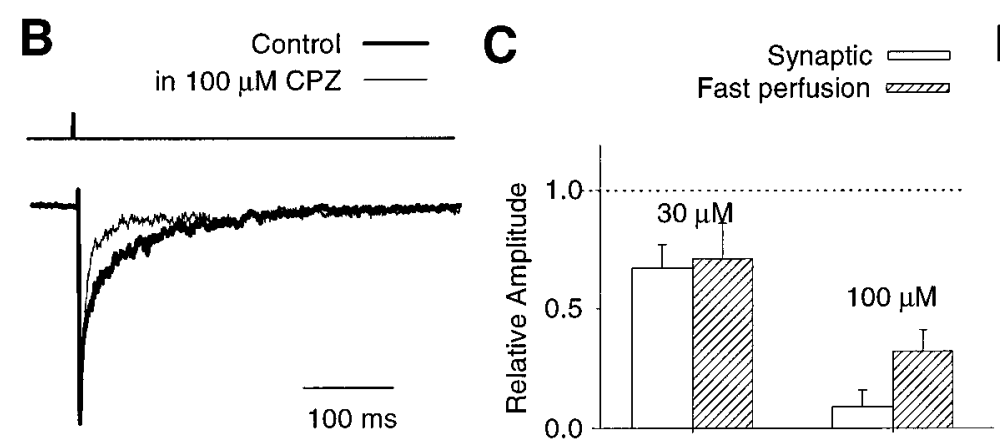

D
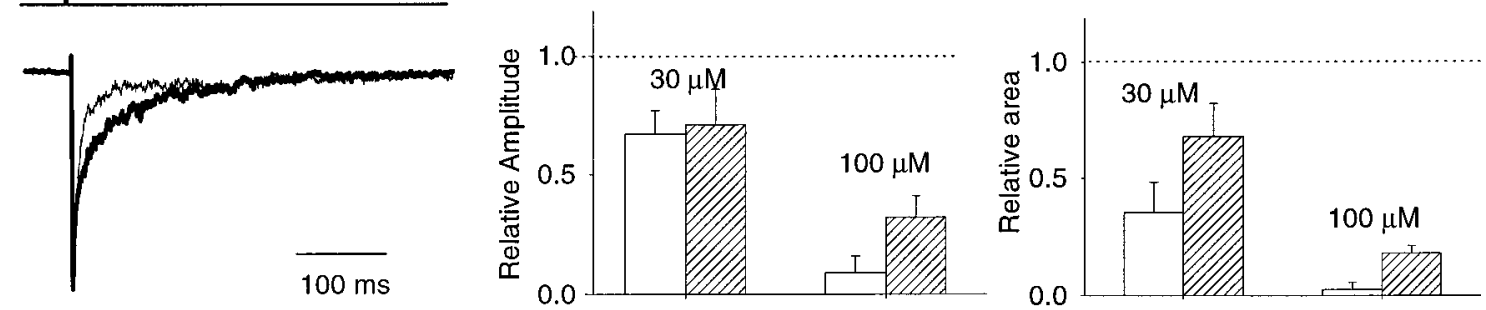

Figure 4. CPZ decreases the amplitude and accelerates the decay kinetics of the currents evoked by brief applications of GABA. $A$, Examples of currents evoked by brief GABA pulses ( $1 \mathrm{~mm}$ for $2 \mathrm{msec}$, inset above the current traces) in control conditions ( $0 \mathrm{CPZ})$ and in the presence of 30 and $100 \mu \mathrm{M}$ CPZ. B, Superimposed, normalized current records shown in $A$ (thick line, control; thin line, in the presence of $100 \mu \mathrm{M} \mathrm{CPZ).} \mathrm{A} \mathrm{clear} \mathrm{acceleration}$ of the decaying phase in the presence of CPZ is evident. $C, \mathrm{CPZ}$ decreases the amplitude of currents evoked by brief GABA applications (hatched bars) in a dose-dependent manner. The comparison is made with the effect of CPZ on mIPSC amplitude (open bars). While at $30 \mu \mathrm{M}$, the effect of CPZ on amplitude of mIPSCs and of GABA-evoked currents is similar; at $100 \mu \mathrm{M} \mathrm{CPZ,} \mathrm{mIPSC}$ amplitude is affected to a larger extent. $D$, Dose dependence of the effect of CPZ on area of GABA-evoked currents (hatched columns) and of mIPSCs (open columns). Both at 30 and $100 \mu \mathrm{M}, \mathrm{CPZ}$ affects the area of mIPSC to a larger extent because of a stronger effect of CPZ on mIPSC decay kinetics (at $30 \mu \mathrm{M}, \mathrm{CPZ}$ had almost no effect on decay of evoked currents). In $C$ and $D$, the values are normalized to the controls (dotted lines).

was $1.12 \pm 0.08 \mathrm{msec}(n=10)$, and in the presence of $100 \mu \mathrm{M}$ $\mathrm{CPZ}$ the rise time was significantly slower $(1.82 \pm 0.06 \mathrm{msec} ; n=$ $10 ; p<0.05)$. The effect of CPZ on the rise time of GABAevoked currents was dose-dependent (Table 2). The observed decrease in the onset rate of GABA-evoked currents indicates that $\mathrm{CPZ}$ interferes with the activation kinetics of $\mathrm{GABA}_{\mathrm{A}}$ receptor. In terms of processes underlying receptor activation, this means that $\mathrm{CPZ}$ affects binding/unbinding rate constants and/or the transition rates between bound and open states. For instance, if $\mathrm{CPZ}$ reduces the binding rate, the presence of the agonist in the synaptic cleft could be too short to activate the receptors to the same extent as in control conditions. However, prolongation of the receptor exposure to agonist would increase the chance of forming bound receptors giving rise to larger currents. This hypothesis was tested by applying GABA pulses of different time duration using the fast perfusion system. As shown in Figure $5 B$, in the presence of $100 \mu \mathrm{M} \mathrm{CPZ}$, the amplitude of GABA-evoked currents clearly increased with time of GABA application (six experiments). On the contrary, in control conditions, application of GABA for time ranging from 1 to $5 \mathrm{msec}$ did not modify either the rise time or the current amplitude (Fig. $5 C$; seven experiments). These results confirm that indeed $\mathrm{CPZ}$ interferes with the activation kinetics of $\mathrm{GABA}_{\mathrm{A}}$ receptors and that such effect is sufficient to decrease GABA-evoked current given that the agonist application is sufficiently short.

A similar effect was obtained by lowering the concentration of GABA from 1 to $0.3 \mathrm{~mm}$ (Fig. $5 D$, four experiments). At such low concentration, binding of GABA (rate $=k_{\mathrm{on}} \cdot$ [GABA]; see also "Modelling" below) becomes rate limiting giving rise to a slower current rise time. Thus, when the presence of agonist is too short (e.g., $1 \mathrm{msec}$ at $0.3 \mathrm{~mm}$ GABA), binding step is not completed, and, consequently, a smaller percentage of receptors can reach the open state.

As it will be discussed in details later, the rising phase depends basically both on binding and unbinding rates and on opening and closing rates of the bound receptor, and, a priori it is difficult to discriminate between these two mechanisms. However, the fact that the binding rate depends on the agonist concentration $\left(k_{\text {on }}\right.$. [GABA]), offers the opportunity to distinguish between these two possibilities. If CPZ lowers the $k_{\text {on }}$ rate constant, its effect on rise time would be equivalent to lowering the concentration of GABA (as in Fig. 4D). Moreover, the effect of CPZ on rise time should be compensated by applying a saturating dose of GABA (e.g., $10 \mathrm{~mm}$ ).

Thus, to test whether CPZ affects the binding kinetics, first 1 $\mathrm{mm}$ and then $10 \mathrm{~mm}$ GABA pulses were applied in the presence of $100 \mu \mathrm{M}$ CPZ. As shown in Figure 6 , application of $10 \mathrm{~mm}$ GABA strongly accelerated the rising phase with respect to 1 mM GABA. Moreover, the time-to-peak of currents evoked by $10 \mathrm{~mm}$ GABA in the presence of $100 \mu \mathrm{M} \mathrm{CPZ}(0.81 \pm 0.06$ msec; $n=6)$ and in control conditions (0.76 $\pm 0.05 \mathrm{msec} ; n=$ 5 ) were not significantly different ( $p>0.3$; Table 2; Fig. 6B, $C$ ). Therefore, the effect of CPZ on rise time of GABA-induced currents can be completely compensated by the increase in 
A

A

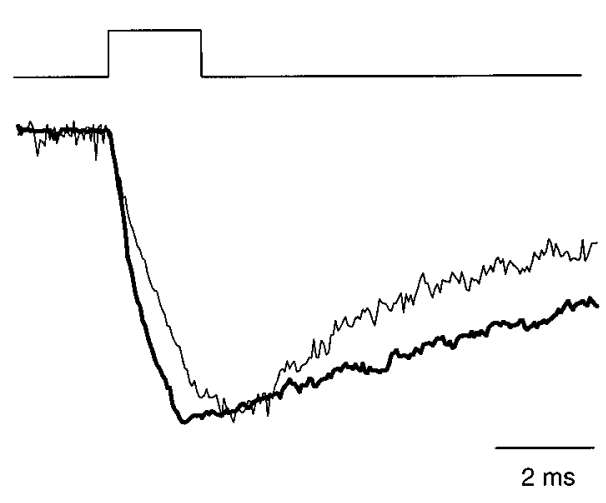

C

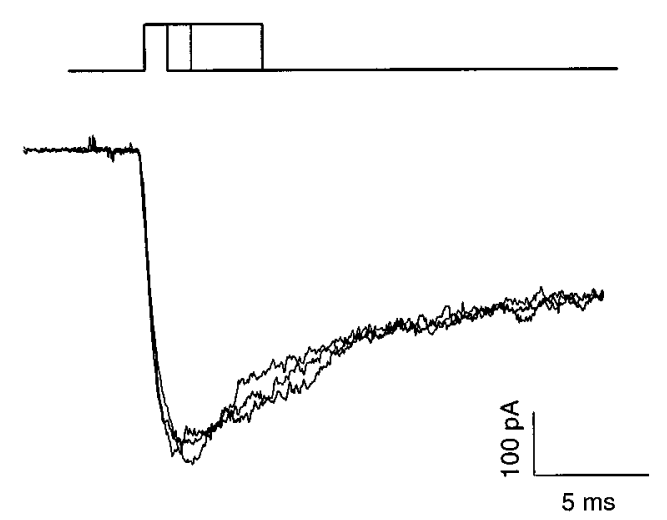

B $1 \mathrm{mM}$ GABA, in $100 \mu \mathrm{M} \mathrm{CPZ}$

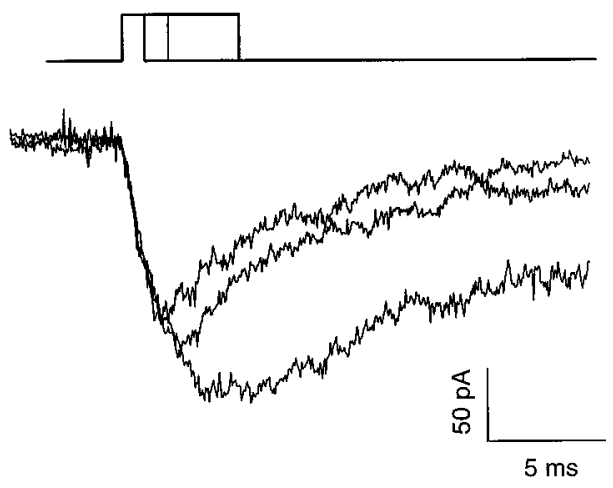

D

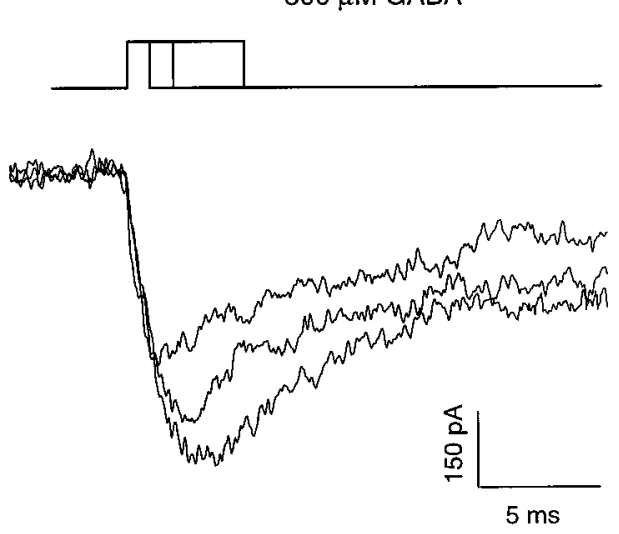

Figure 5. CPZ affects the rising phase of currents evoked by brief pulses of GABA. $A$, Examples of normalized currents evoked by brief GABA applications ( $1 \mathrm{~mm}$ GABA for $2 \mathrm{msec}$ ) in control conditions (thick line) and in the presence of $100 \mu \mathrm{M} \mathrm{CPZ} \mathrm{(thin} \mathrm{line).} \mathrm{A} \mathrm{clearly} \mathrm{slower} \mathrm{rate} \mathrm{of} \mathrm{current}$ onset is seen in the presence of CPZ. B, Currents evoked in the presence of $100 \mu \mathrm{M} \mathrm{CPZ} \mathrm{by} 1 \mathrm{~mm}$ GABA pulses of different time duration (1, 2, and $5 \mathrm{msec}$ ). The current amplitude and the time-to-peak increased with time of GABA application. $C$, Currents evoked by GABA (1 mM) were applied for the same time intervals as in $B(1,2$, and $5 \mathrm{msec})$ but in the absence of CPZ. Time duration of GABA pulse within this range had no effect on the time course of the currents. $D$, Currents evoked by $300 \mu \mathrm{M}$ GABA pulses of 1,2 , and $5 \mathrm{msec}$ duration. At this GABA concentration, the time duration of GABA pulses had qualitatively similar effect on the rising phase as in the case of $1 \mathrm{~mm}$ GABA in the presence of $100 \mu \mathrm{M} C P Z(B)$. The insets above current traces indicate the time course of GABA application.

GABA concentration. In addition, at variance to $1 \mathrm{~mm}$ GABA responses (Fig. 5B), when applying $10 \mathrm{~mm}$ GABA pulses of various time duration $(1,2$, or $5 \mathrm{msec})$ in the presence of $100 \mu \mathrm{M}$ $\mathrm{CPZ}$, no differences either in amplitude or in time course were seen (Fig. 6D, three experiments). Interestingly, on average, the amplitude of currents evoked by $10 \mathrm{~mm}$ GABA in the presence of $100 \mu \mathrm{M} \mathrm{CPZ}$ was only slightly smaller than that induced by the same GABA concentration in control conditions (Fig. 6E). This observation indicates that most of the observed CPZ-induced decrease in the amplitude of the GABA-evoked current was caused by a decrease in the binding rate.

\section{Desensitization kinetics}

In previous studies, Jones and Westbrook (1995, 1996) have demonstrated that the desensitization process of $\mathrm{GABA}_{\mathrm{A}}$ receptors plays an important role in shaping inhibitory synaptic currents. These authors proposed that sojourns in the desensitized states preceding channel reopening effectively prolong the synaptic currents. Such single-channel openings separated by silent periods (sojourn in the desensitized state) were also observed in our experiments (Fig. 7A). This finding indicates that also, in our case, desensitization participates in shaping mIPSCs and raises the possibility that CPZ could affect mIPSC decay kinetics by a modulation of the desensitization process. To test this hypothesis, long pulses of saturating doses of GABA $(10 \mathrm{mM})$ were applied in the presence and in the absence of $100 \mu \mathrm{M} \mathrm{CPZ}$. In these conditions, the binding reaction is not rate limiting, and the current time course is supposed to depend only on the opening and closing rates and desensitization kinetics. As shown in Figure 7, $B$ and $C$, the currents evoked by long pulses of GABA $(\geq 200$ msec) could be well fitted by the sum of two exponentials (Eq. 1, Materials and Methods), indicating the presence of two desensitization components (in control: $\tau_{\text {fast }}=8.7 \pm 0.9 \mathrm{msec}, A_{\text {fast }}=$ $0.38 \pm 0.03, \tau_{\text {slow }}=263 \pm 56 \mathrm{msec}, A_{\text {slow }}=0.35 \pm 0.04, A_{\mathrm{s}}=$ $0.17 \pm 0.05, n=6$; in $100 \mu \mathrm{M} \mathrm{CPZ:} \tau_{\text {fast }}=9.4 \pm 0.9 \mathrm{msec}$, $A_{\text {fast }}=0.59 \pm 0.05, \tau_{\text {slow }}=143 \pm 38 \mathrm{msec}, \mathrm{A}_{\text {slow }}=0.21 \pm 0.02$, $\left.A_{\mathrm{s}}=0.16 \pm 0.04\right)$. The time constants of the fast components of the current decay were not statistically different $(p>0.5)$, indicating that the onset rate of the fast desensitization was not 

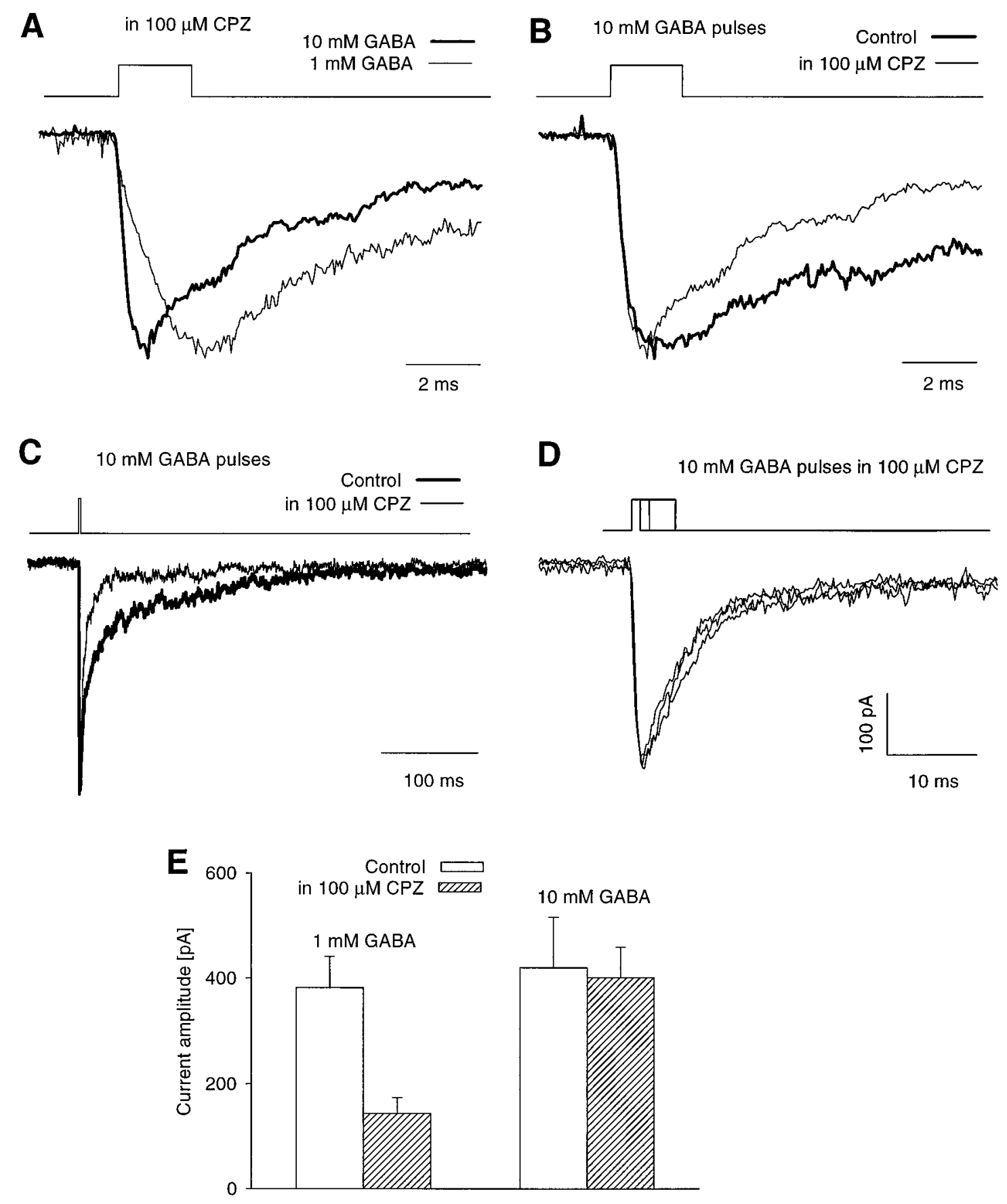

Figure 6. Effect of $\mathrm{CPZ}$ on the rising phase of GABA-evoked currents can be reversed by saturating GABA concentrations. In contrast, the CPZ-induced acceleration of deactivation current cannot be compensated by increasing doses of GABA. $A$, Examples of currents evoked by 2 msec pulse of $1 \mathrm{~mm}$ (thin line) and $10 \mathrm{~mm}$ GABA (thick line) in the presence of $100 \mu \mathrm{M} \mathrm{CPZ.} B$, The rising phases of currents evoked by $10 \mathrm{~mm}$ GABA in control conditions (thick line) and in the presence of $100 \mu \mathrm{M} \mathrm{CPZ} \mathrm{(thin} \mathrm{line)} \mathrm{have} \mathrm{indistinguishable} \mathrm{onset} \mathrm{kinetics.} C$, The current traces shown in $B$ are plotted in a different time scale. A clearly faster decay kinetics is seen in the presence of $100 \mu \mathrm{M} \mathrm{CPZ}$. $D$, Currents evoked by $10 \mathrm{~mm}$ GABA pulses applied for 1,2 , and $5 \mathrm{msec}$ in the presence of $100 \mu \mathrm{M} \mathrm{CPZ}$. Within this range, time duration of GABA pulse had no effect on the current time course. In $A-D$, the insets above current traces indicate the time course of GABA application. $E$, Absolute values of mean amplitudes of currents evoked by GABA pulses $(2 \mathrm{msec})$ in conditions described above the columns. In particular, the current amplitudes evoked by $10 \mathrm{~mm}$ GABA in the presence and in the absence of CPZ were not significantly different $(p>0.4)$.

affected by CPZ. There was a difference in the percentage of the slow component of desensitization in controls and in the presence of CPZ $(p<0.05)$. However, because the time constant of slow desensitization is as slow as $>150 \mathrm{msec}$ (rate of onset $<0.007$ $\left.\mathrm{msec}^{-1}\right)$, it is unlikely that this component would have any significant impact on the currents evoked by very brief GABA applications. Consequently, the lack of effect on CPZ on the kinetics of fast desensitization component indicates that the observed effect of CPZ on the deactivation is not caused by modification of the desensitization kinetics. 
A

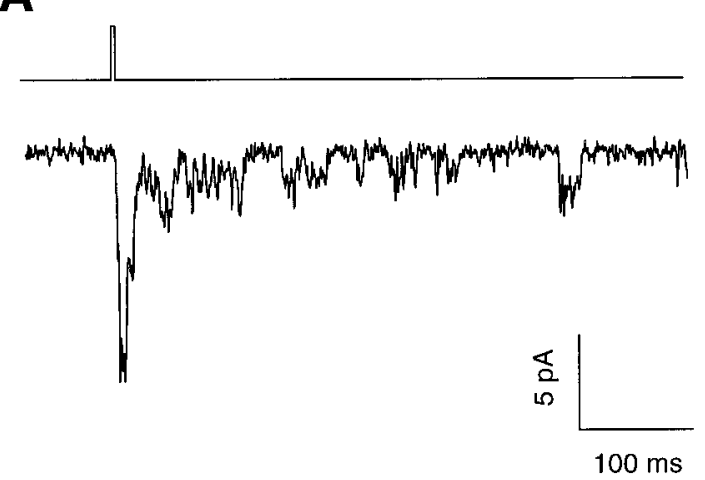

B

Control

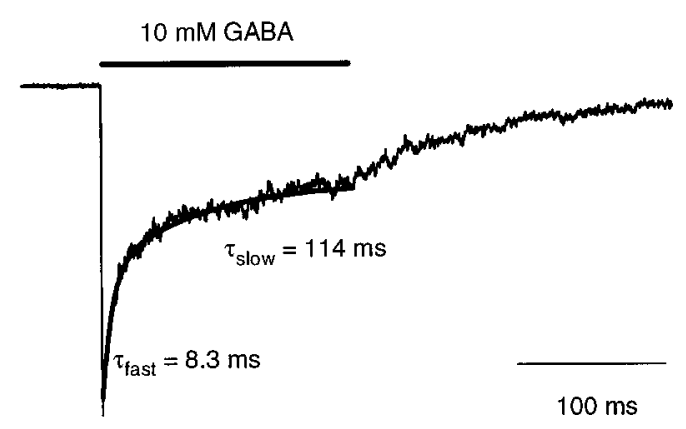

C

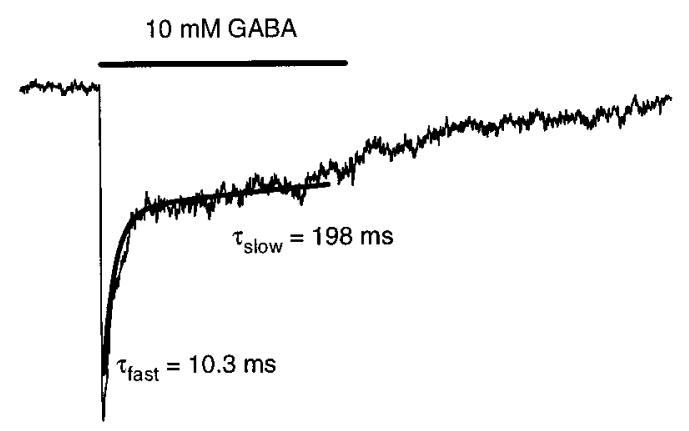

Figure 7. The onset of the fast desensitization component is not affected by CPZ. A, Example of a current evoked by GABA pulse (1 mM for 2 msec, see inset above the current trace) in which single-channel activity can be observed. During the deactivation phase (after removal of GABA), the single-channel openings are separated by silent periods indicating sojourns in a desensitized state. $B, C$, Examples of normalized current responses to long $(200 \mathrm{msec})$ GABA applications $(10 \mathrm{mM}$, solid bars) in control conditions $(B)$ and in the presence of $100 \mu \mathrm{M} C P Z(C)$. The decaying phases, during GABA applications, were fitted with Equation 1 (Materials and Methods). Time constants are specified below the traces, and the steady-state fractions of currents $\left(A_{\mathrm{s}}\right)$ are 0.21 and 0.17 for control and in the presence of $100 \mu \mathrm{M}$ CPZ, respectively.

\section{Kinetic modelling of currents evoked by brief GABA pulses}

To provide a better quantitative description of the effect of CPZ on $\mathrm{GABA}_{\mathrm{A}}$ receptors, a kinetic model was investigated. The model (Fig. 8A) proposed by Jones and Westbrook (1995) allows to predict all major properties of currents evoked by brief GABA applications. However, to adopt the model to our experimental data, the values of the rate constants were readjusted. The main difference between the prediction given by Jones and Westbrook's parameters and our experimental data were the rise time of the responses evoked by brief GABA $(1 \mathrm{~mm})$ pulses $(\sim 2 \mathrm{msec}$, Jones and Westbrook's model; $1.12 \pm 0.08 \mathrm{msec}$, our experimental data). Moreover, using their parameters, an increase in amplitude by $\sim 10 \%$ was predicted when increasing the time of GABA ( 1 $\mathrm{mM}$ ) application from 1 to $5 \mathrm{msec}$. This finding is contrary to our experimental data, as shown in Figure 5C, variation of application time within this interval did not lead to any significant change either in amplitude or in the time course of GABA-evoked currents. A good reproduction of the rising phase kinetics (Fig. $9 A, B)$ was obtained by increasing the binding rate constant $\left(k_{\text {on }}\right)$ and the rate of transition from doubly bound to open state $\left(\beta_{2}\right)$ to the values indicated in Figure $8 B$. The decaying phase was well reproduced by setting the unbinding rate $k_{\text {off }}$ and the rate constants governing the fast desensitization kinetics $\left(\mathrm{d}_{2}, \mathrm{r}_{2}\right)$ as shown in Figure $8 B$. In the simulations of responses to fast GABA applications ( $\geq 1 \mathrm{~mm} ; \geq 1 \mathrm{msec}$ ) using the values of parameters as indicated in Figure $8 B$, the occupancy of the singly bound open state $\left(\mathrm{AR}^{*}\right)$ was very small $(<2 \%)$.

\section{Kinetic modelling of currents evoked by brief GABA pulses in the presence of CPZ}

The model simulations were also used to explore the mechanisms underlying the observed effects of CPZ. The main differences between the responses recorded in the presence of $\mathrm{CPZ}$ and control ones were: (1) slower rise time, (2) faster deactivation kinetics, and (3) lower amplitude. As already mentioned, a decrease in the rate of onset of the GABA-evoked current could potentially involve modifications in: $k_{\text {on }}, k_{\text {off }}, \beta_{2}$ and $\alpha_{2}$. As shown in Figure $9 C, D$, lowering $k_{\text {on }}$ is sufficient to predict a decrease both in amplitude (Fig. 9C) and in the rate of onset (Fig. 9D). Because $\beta_{2}$ and $\alpha_{2}$ are assumed not to depend on agonist concentration, the following observations argue against the possibility that the observed effect of $\mathrm{CPZ}$ on the current onset is related to modifications of these rate constants: (1) a decrease in the onset rate of current evoked by $1 \mathrm{~mm}$ GABA, observed in the presence of $100 \mu \mathrm{M} \mathrm{CPZ} \mathrm{(Fig.} \mathrm{5A),} \mathrm{can} \mathrm{be} \mathrm{reversed} \mathrm{by} \mathrm{increasing}$ GABA concentration (Fig. 6A), (2) the onset kinetics of currents evoked by a saturating GABA concentration $(10 \mathrm{mM})$ in control conditions and in the presence of $100 \mu \mathrm{M} \mathrm{CPZ}$ are indistinguishable (Fig. $6 B$ ), and (3) the currents evoked by $10 \mathrm{~mm}$ GABA in control conditions and in the presence of $100 \mu \mathrm{M} \mathrm{CPZ} \mathrm{have} \mathrm{very}$ similar amplitudes (Fig. 6E). In addition, when modelling the 
A

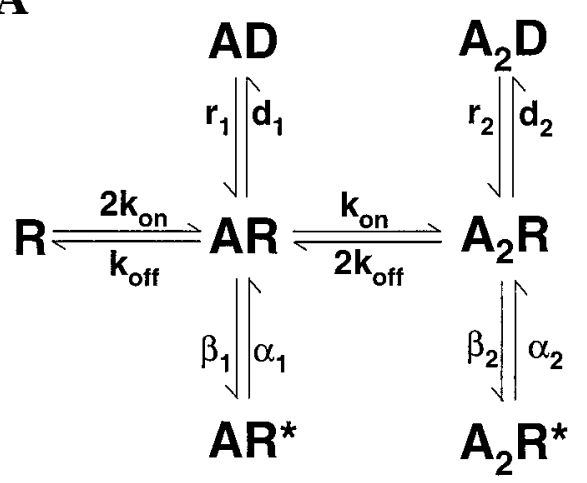

B

\begin{tabular}{|c|c|c|}
\hline Constant & Control & $\mathbf{1 0 0} \mu \mathbf{M ~ C P Z}$ \\
\hline $\mathrm{k}_{\mathrm{on}}\left[\mathrm{ms}^{-1} \mathrm{mM}^{-1}\right]$ & $10-15$ & $1-2$ \\
\hline $\mathrm{k}_{\mathrm{off}}\left[\mathrm{ms}^{-1}\right]$ & $0.2-0.3$ & $0.4-0.6$ \\
\hline$\beta_{1}\left[\mathrm{~ms}^{-1}\right]$ & 0.2 & 0.2 \\
\hline$\alpha_{1}\left[\mathrm{~ms}^{-1}\right]$ & 1.1 & 1.1 \\
\hline $\mathrm{d}_{1}\left[\mathrm{~ms}^{-1}\right]$ & 0.013 & 0.013 \\
\hline $\mathrm{r}_{1}\left[\mathrm{~ms}^{-1}\right]$ & 0.00013 & 0.00013 \\
\hline$\beta_{2}\left[\mathrm{~ms}^{-1}\right]$ & $6-10$ & $6-10$ \\
\hline$\alpha_{2}\left[\mathrm{~ms}^{-1}\right]$ & $0.25-0.3$ & $0.25-0.3$ \\
\hline $\mathrm{d}_{2}\left[\mathrm{~ms}^{-1}\right]$ & $1.0-2.0$ & $1.0-2.0$ \\
\hline $\mathrm{r}_{2}\left[\mathrm{~ms}^{-1}\right]$ & $0.035-0.045$ & $0.035-0.045$ \\
\hline
\end{tabular}

Figure 8. Quantitative model of $\mathrm{GABA}_{\mathrm{A}}$ channel gating (from Jones and Westbrook, 1995). $A$, Scheme of transitions available for the channel. It is assumed that the receptor $R$ has two independent binding sites for the agonist $A$ (bound states: $A R, A_{2} R$ ). The channel may reach the open states $\left(A R^{*}, A_{2} R^{*}\right)$ both from singly and doubly bound states. The model postulates also the singly and doubly bound desensitized states $(A D$, $\left.A_{2} D\right) . B$, Values of the rate constants reproducing the current responses to GABA in control conditions and in the presence of $100 \mu \mathrm{M} \mathrm{CPZ}$.

effect of CPZ by decreasing $\beta_{2}$ (leaving $k_{\text {on }}$ unchanged), it was impossible to reproduce the increase in current amplitude (Fig. $5 B$ ) with duration of GABA application (simulation not shown). It is worth emphasizing that although the rate of binding reaction is determined by the reciprocal of $\left(k_{\text {on }} \cdot[\mathrm{GABA}]+k_{\text {off }}\right)$, the kinetics of this process is dominated by the binding rate both in control conditions and in the presence of CPZ $\left(k_{\text {on }} \cdot[\mathrm{GABA}] \gg\right.$ $k_{\text {off }}$ at $[\mathrm{GABA}] \geq 1 \mathrm{mM}$, see also below for $k_{\text {off }}$ value). In our model, we mimicked the effect of $100 \mu \mathrm{M} \mathrm{CPZ}$ on the current onset by lowering the value of $k_{\text {on }}$ to $1-2 \mathrm{~mm} / \mathrm{msec}$ (Fig. $8 B$ ), leaving the values of $\beta_{2}$ and $\alpha_{2}$ unchanged.

In our experiments we have also observed a very pronounced effect of $\mathrm{CPZ}$ on the decay kinetics of the evoked currents (Figs. $4 C, 6 C)$. A decrease in $k_{\text {on }}$, which accounts for the slower current onset and lower peak open probability, is insufficient to predict such strong acceleration of the current decay (Figs. 3, 4, 9C,D). Although, as shown in Figure $9 D$, a decrease in the binding rate to $k_{\mathrm{on}}=1.5 \mathrm{~mm} / \mathrm{msec}$ gives rise to an acceleration of decay, but when increasing GABA concentration, a time course identical to control is restored. The last prediction results from the fact that the rate of binding reaction is determined by the product $k_{\text {on }}$. [GABA] and, obviously, when multiplying [GABA] by the same factor ( 8 in Fig. $9 C, D$ ) by which $k_{\text {on }}$ was divided, the model resumes perfectly the control conditions. The acceleration of the decay kinetics obtained at $k_{\text {on }}=1.5 \mathrm{~mm} / \mathrm{msec}$ results from an increased probability of singly liganded open receptors $\left(\mathrm{AR}^{*}\right.$, see legend of Fig. 9). Because the rate constant $d_{1}$ is much smaller than $d_{2}$, the singly bound desensitized state (AD) cannot contribute to the decay kinetics to the same extent as $\mathrm{A}_{2} \mathrm{D}$. However, in our experiments, the effect of CPZ on the decay kinetics was present also at saturating GABA concentration (10 mM, Fig. $6 C$ ), indicating that other factors than $k_{\text {on }}$ must be also involved. In previous investigations, Jones and Westbrook (1995, 1997) pointed out that the decay kinetics of the deactivation currents strongly depends on the balance between the unbinding rate $k_{\text {off }}$ and the rate constants governing the fast desensitization $\left(A_{2} D\right)$. The reason for such relation is that the slower is the unbinding rate, the larger is the probability of "visiting" the desensitized state that, as already mentioned, leads to a prolongation of the deactivation currents. Thus, it is likely that the accelerated deactivation, observed in the presence of CPZ, involves a modification of the unbinding rate $k_{\text {off }}$ and/or of the fast desensitization kinetics. However, our data show that the onset kinetics of the fast desensitization is not affected by CPZ. In addition, as already mentioned, the slower desensitization phase is unlikely to affect the kinetics of the decay currents and for this reason this component was omitted in our model.

A good prediction of the effect of CPZ on the deactivation kinetics was obtained by increasing the value of the unbinding rate $k_{\text {off }}$. As shown in Figure 9, $E$ and $F$, an increase in the unbinding rate from $k_{\text {off }}=0.25 \mathrm{msec}^{-1}$ to $0.5 \mathrm{msec}^{-1}$, leads to a strong acceleration of the decay kinetics. When setting $k_{\text {off }}=0.5$ $\operatorname{msec}^{-1}\left(k_{\text {on }}=1.5 \mathrm{~mm} / \mathrm{msec}\right)$, the faster deactivation kinetics is clearly present both in current evoked by 1 and $10 \mathrm{~mm}$ GABA (Fig. $9 F$ ). Moreover, as seen in Figure $9 F$, the currents evoked by 10 mM GABA in control conditions and in the "presence of CPZ" $\left(k_{\text {on }}=1.5 \mathrm{~mm} / \mathrm{msec} ; k_{\text {off }}=0.5 \mathrm{msec}^{-1}\right)$ have almost identical rising phases. These model predictions basically reproduce the effects of $\mathrm{CPZ}$ on current responses to fast GABA applications observed in our experiments (compare Figs. $5 A, B$, $6 B$ with Fig. $9 E, F)$. Thus, the lack of effect of $\mathrm{CPZ}$ on the fast desensitization component and the above model simulation provide clear, although indirect, evidence that the mechanism underlying the acceleration of the deactivation kinetics is an increase in the unbinding rate $k_{\text {off }}$.

In conclusion, the investigations described above show that the necessary requirement for a qualitative reproduction of the effect of CPZs on currents evoked by fast GABA application is a decrease in the binding and increase in the unbinding rate constants $k_{\text {on }}$ and $k_{\text {off }}$, respectively.

\section{Kinetic modelling of mIPSCs in control conditions and in the presence of CPZ}

In the previous sections we have pointed out that the currents evoked by brief pulses of GABA closely resembled mIPSCs and that the effects of $\mathrm{CPZ}$ on these currents were qualitatively similar. There were, however, some differences: (1) CPZ had no effect on the rising phase of the mIPSC but strongly affected the 

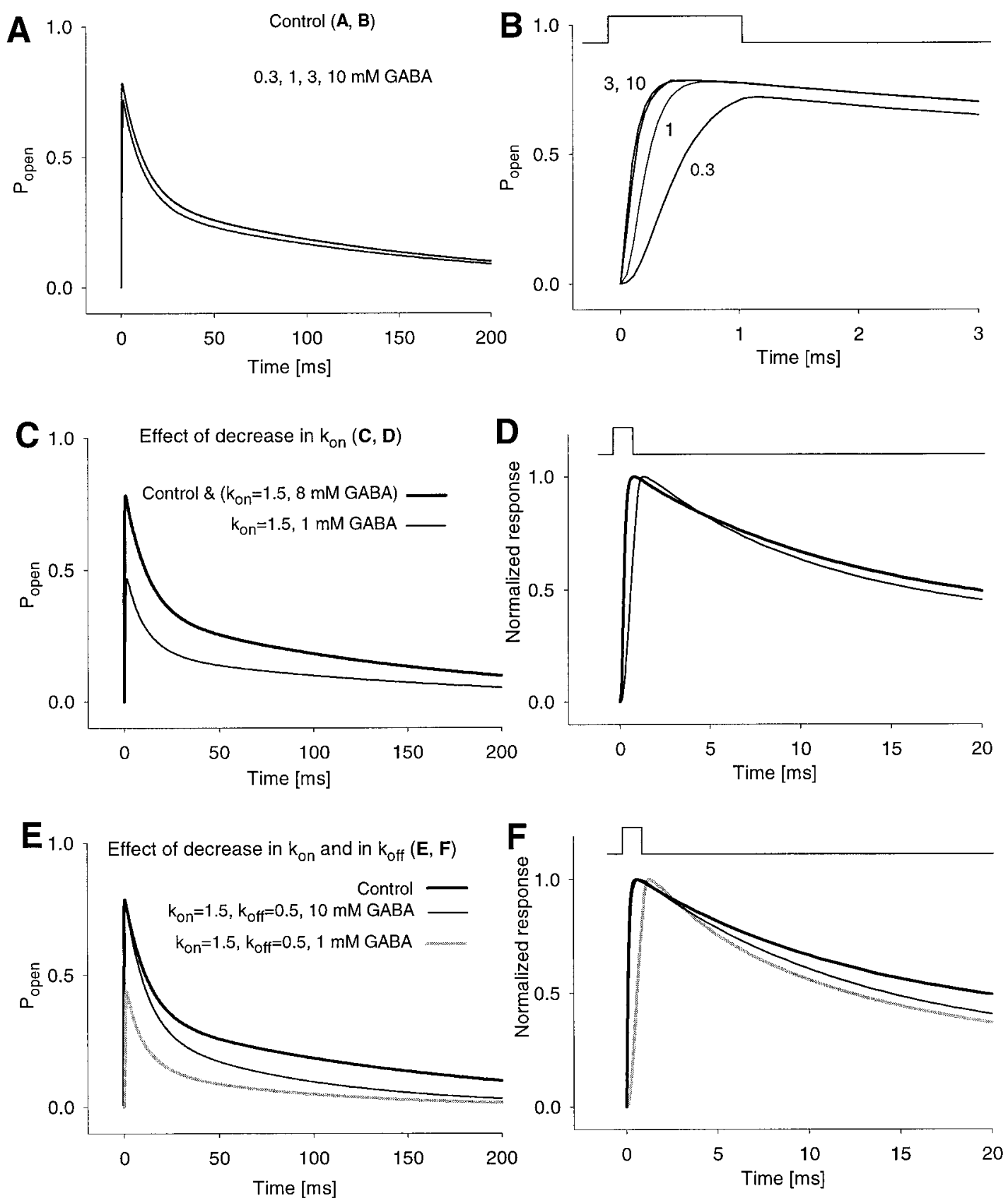

Figure 9. Kinetic modelling of current responses to brief pulses of GABA in control conditions and in the presence of CPZ. Decrease in the binding rate $k_{\text {on }}$ and increase in the unbinding rate $k_{\text {off }}$ reproduces qualitatively the effects of CPZ. $A$, Control responses evoked by 1 msec pulses of GABA at different concentrations. For these simulations, the following values of rate constants were assumed: $k_{\text {on }}=12 \mathrm{mM} / \mathrm{msec}, k_{\text {off }}=0.25 \mathrm{msec}-1, \beta_{1}=0.2$ $\mathrm{msec}^{-1}, \alpha_{1}=1.1 \mathrm{msec}^{-1}, d_{1}=0.013 \mathrm{msec}^{-1}, r_{1}=0.00013 \mathrm{msec}^{-1}, \beta_{2}=8 \mathrm{msec}^{-1}, \alpha_{2}=0.285 \mathrm{msec}^{-1}, d_{2}=1.7 \mathrm{msec}^{-1}$, and $r_{2}=0.04 \mathrm{msec}-1 . B, \mathrm{Same}^{-1}$ traces shown in $A$ in an expanded time scale. The onset of GABA responses saturates at $\sim 3$ mM GABA. $C$, Modelling of the effect of CPZ on GABA-evoked currents by decreasing $k_{\text {on }}$ rate constant $\left(k_{\text {on }}=1.5 \mathrm{msec}^{-1}\right.$, other kinetic parameters are unchanged, thin line). Thick line, control (rate constants as indicated for simulations shown in $A$ and $B$ ). The identical time course to the control (1 mM GABA for $1 \mathrm{msec})$ was obtained when applying $8 \mathrm{~mm}$ GABA ( $1 \mathrm{msec})$ assuming $k_{\mathrm{on}}=1.5 \mathrm{msec}^{-1}$ because in these conditions $k_{\text {on }} \cdot$ [GABA] is equal to that in control conditions $\left(k_{\text {on }}=12 \mathrm{msec}{ }^{-1}\right.$, $[\mathrm{GABA}]=1 \mathrm{~mm}) . D$, The same traces as in $C$, after normalization and in an expanded time scale. A clear decrease in the onset rate as well as a moderate acceleration of the decay is seen when $k_{\mathrm{on}}=1.5 \mathrm{msec}^{-1}$. However, an increase in GABA concentration (to 8 mM), reverses both effects. For control $P_{\mathrm{AR}^{*}} / P_{\text {open }}=0.017$ and in the case of $k_{\mathrm{on}}=1.5$ (other parameters unchanged), $P_{\mathrm{AR}^{*}} / P_{\mathrm{open}}=0.107$, where $\mathrm{P}_{\mathrm{AR}^{*}}=$ maximum open probability of singly bound open state $\left(\mathrm{AR}^{*}\right)$ and $P_{\text {open }}=$ total maximum open probability. $E$, Modelling the effect of $\mathrm{CPZ}$ by decreasing the binding rate (to $k_{\mathrm{on}}=1.5$ $\mathrm{msec}^{-1}$ ) and by increasing the unbinding rate (to $\left.k_{\mathrm{off}}=0.5 \mathrm{msec}^{-1}\right)$. Thick line, Control $(1 \mathrm{~mm}$ GABA for $1 \mathrm{msec})$. Thin line, $\left(k_{\mathrm{on}}=1.5 \mathrm{msec}-1, k_{\mathrm{off}}\right.$ $=0.5 \mathrm{msec}^{-1}$, other parameters unchanged, $10 \mathrm{~mm}$ GABA for $1 \mathrm{msec}$ ), in this case, the amplitude is very close to that in control, but the decay is clearly faster. Thick gray line, $\left(k_{\mathrm{on}}=1.5 \mathrm{msec}^{-1}, k_{\mathrm{off}}=0.5 \mathrm{msec}^{-1}\right.$, other parameters unchanged, $1 \mathrm{mM}$ GABA for $\left.1 \mathrm{msec}\right) . F$, The same traces as in $E$ but normalized and in an expanded time scale. Control and response to $10 \mathrm{mM} \mathrm{GABA}$ application at $k_{\mathrm{on}}=1.5 \mathrm{msec}^{-1}$ and $k_{\text {off }}=0.5 \mathrm{msec}-1$ have very similar rise time, but the latter has faster decay. One micromolar GABA application $(1 \mathrm{msec})$ at $k_{\mathrm{on}}=1.5 \mathrm{msec}^{-1}$ and $k_{\text {off }}=0.5 \mathrm{msec}{ }^{-1}$ has slower rise time and faster decay than control. Moreover, at $\left(k_{\mathrm{on}}=1.5 \mathrm{msec}^{-1}, k_{\mathrm{off}}=0.5 \mathrm{msec}^{-1}\right) 1 \mathrm{~mm} \mathrm{GABA}$, response has faster decay than that to $10 \mathrm{~mm}$ GABA. The values of $P_{\mathrm{AR}^{*}} / P_{\mathrm{open}}$ are: 0.017 (control), $0.014\left(k_{\mathrm{on}}=1.5 \mathrm{msec}^{-1}, k_{\mathrm{off}}=0.5 \mathrm{msec}^{-1}, 10 \mathrm{mM} \mathrm{GABA}\right), 0.11\left(k_{\mathrm{on}}=1.5 \mathrm{msec}-1, k_{\mathrm{off}}=0.5 \mathrm{msec}-1\right.$, 1 mM GABA). In $B, D, F$, insets above the curves indicate the time course of the agonist. 
A

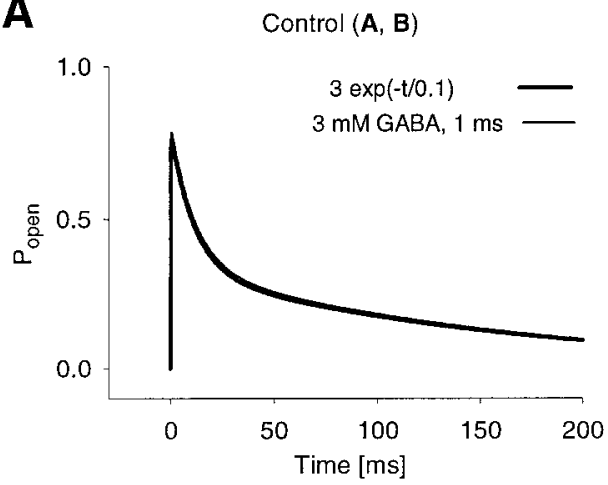

C

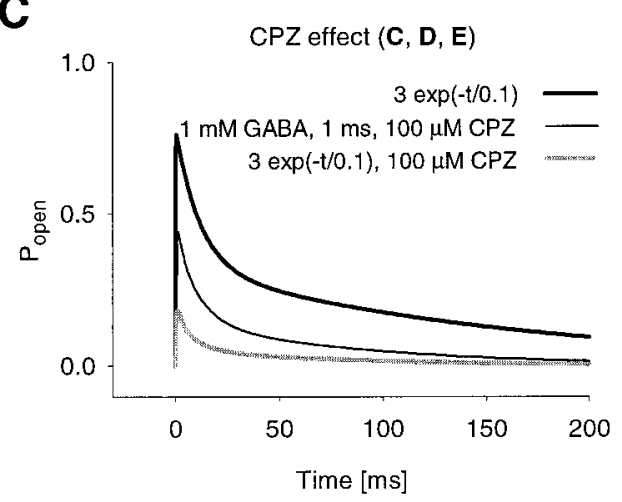

B

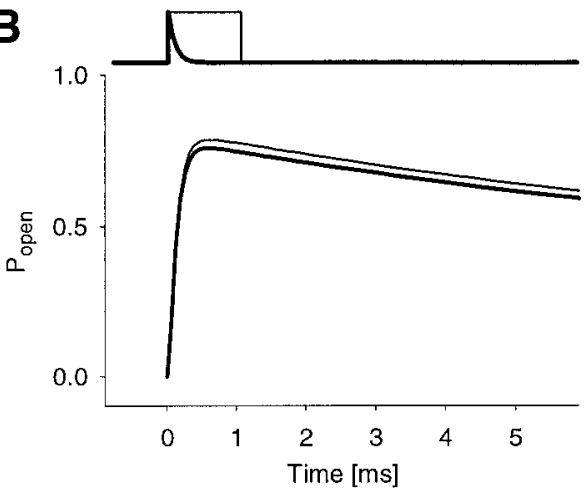

D

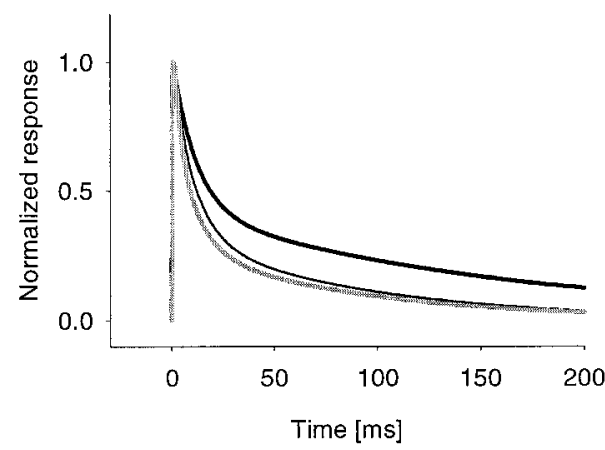

Figure 10. Kinetic modelling of mIPSCs in control conditions and in the presence of CPZ. The synaptic current is modelled by current response to "exponential application": $A \cdot \exp (-t / \tau), A=3$ $\mathrm{mM}, \tau=0.1 \mathrm{msec}$. $A, B$, Comparison of mIPSC (thick line) to response to GABA pulse (thin line, $3 \mathrm{~mm}$ for $1 \mathrm{msec}$ ). The decaying $(A)$ and rising phases $(B)$ of the two currents are very similar. The peak open probability for mIPSC is slightly $(<5 \%)$ smaller that that for the response elicited by 1 msec GABA pulse. $C$, Comparison of the effect of CPZ on mIPSC and on responses evoked by GABA pulse. Thick line, Control mIPSC; thick gray line, mIPSC in the presence of CPZ $\left(k_{\text {on }}=1.5 \mathrm{msec}^{-1}, k_{\text {off }}\right.$ $\left.=0.5 \mathrm{msec}^{-1}\right)$; thin line, response to GABA (1 mM for $1 \mathrm{msec})$ in the presence of CPZ. The CPZ treatment diminishes the mIPSC amplitude to a larger extent than that of current evoked by 1 msec GABA pulse. $D$, The same traces as in $C$ after normalization. CPZ accelerates the decay both of mIPSC and of response to $1 \mathrm{msec}$ GABA pulse. In the case of mIPSC, the decay acceleration is slightly larger than that of response to GABA pulse. The values of $P_{\mathrm{AR}^{*}} / P_{\mathrm{open}}$ are: 0.009 (control mIPSC), 0.25 (mIPSC in the presence of CPZ: $k_{\mathrm{on}}=$ $\left.1.5 \mathrm{msec}^{-1}, k_{\text {off }}=0.5 \mathrm{msec}^{-1}\right), 0.11$ $\left(k_{\text {on }}=1.5 \mathrm{msec}^{-1}, k_{\text {off }}=0.5 \mathrm{msec}^{-1}, 1\right.$ $\mathrm{mM}$ GABA), where $\mathrm{P}_{\mathrm{AR}^{*}}=$ maximum open probability of singly bound open state $\left(\mathrm{AR}^{*}\right)$ and $P_{\text {open }}=$ total maximum open probability. $E$, The same traces as in $D$ in an expanded time scale. The slowest rate of onset is predicted for GABA responses ( $1 \mathrm{~mm}$ for $1 \mathrm{msec})$ in the presence of CPZ. The rise time of mIPSC is only slightly affected by CPZ. $B, E$, Insets above the traces indicate the time course of agonist in the case of mIPSC (thick line) and GABA application (thin line). onset of the evoked currents and (2) at $100 \mu \mathrm{M}$ concentration, CPZ decreased the amplitude of the synaptic currents to a larger extent than that of the evoked ones. It is possible that a source of these discrepancies is that the time course of the agonist applied using our perfusion system differs from that in the synaptic cleft. Although the time course of applied GABA concentration is expected to be of nearly rectangular shape, the time evolution of agonist in the synapse is different. The simulations as well as experiments (for review, see Clements, 1996) indicate that in the synapse, the onset of agonist concentration is very fast (time-topeak $\sim 10^{1} \mu \mathrm{sec}$ ), and its clearance is characterized predominantly by a time constant in the range between $5 \times 10^{1}$ and $10^{2}$ $\mu$ sec (Clements, 1996; Silver et al., 1996). Because no perfusion system is able to apply the agonist with such kinetics, the model simulations offer a unique opportunity to explore the effects of CPZ on mIPSCs by extrapolating our experimental findings to the situation in the synapse. To simulate the synaptic response, the time course of the agonist was modelled by an exponential function: $A \cdot \exp (-t / \tau)$, where $A$ is the maximum value of the agonist concentration and $\tau$, the time constant. The time constant $\tau$ was chosen to be $100 \mu \mathrm{sec}$ because, as it will be discussed later, a slower time constant of the agonist clearance (e.g., 200 or 300 $\mu \mathrm{sec})$ would lead to a clear decrease in the "mIPSC" onset rate in the presence of CPZ (not seen in the experiments, Fig. 1D). This value of agonist decay rate is in agreement with studies on the time course of agonist in the synapse (Clements, 1996; Silver et al., 1996). The peak concentration $A=3 \mathrm{~mm}$ was chosen to assure the saturation of mIPSC. For instance, when choosing $A=1 \mathrm{~mm}$, the maximum open probability was $<0.4$, and when increasing $A$, the maximum $P_{\text {open }}$ increased substantially, reaching saturation at $A \geq 3 \mathrm{~mm}$ ( $P_{\text {open }} \sim 0.78$ at saturation). Thus, these simulations indicate that the peak synaptic concentration is at least $3 \mathrm{~mm}$, as it is known that GABA released in the synapse is sufficient to saturate the amplitude of mIPSC (Mody et al., 1994). As shown in Figure 10, $A$ and $B$, the synaptic currents modelled by "exponential agonist application" with parameters $A=3 \mathrm{~mm}$ and $\tau=$ $100 \mu \mathrm{sec}$ had the rise time and decay kinetics almost indistinguishable from those obtained when simulating responses evoked 
by $1 \mathrm{msec}$ pulses of $3 \mathrm{~mm}$ GABA. There was only a small difference in the maximum open probability $(<5 \%$, Fig. $10 B)$.

As discussed above, the effect of CPZ was simulated by decreasing the binding rate $k_{\text {on }}$ and by increasing the unbinding rate $k_{\text {off }}$ (as indicated in Fig. $8 B$ ). As shown in Figure 10C, the CPZ treatment results in a strong reduction in mIPSC amplitude, notably larger than in the case of effect of CPZ on the evoked currents. This prediction is in agreement with experimental observation that CPZ $(100 \mu \mathrm{M})$ diminishes mIPSCs amplitudes to a larger extent than that of the evoked currents (Fig. 4C). The simulation of the effect of CPZ on mIPSCs reproduced also the acceleration of the current decay kinetics (Fig. 10D). Moreover, in agreement with the experimental data, in the presence of $\mathrm{CPZ}$, the acceleration of deactivation is stronger for mIPSCs than for the currents evoked by brief pulses of GABA (Fig. 10D). This difference is a consequence of a larger proportion of singly bound open states $\left(\mathrm{AR}^{*}\right)$ in the case of mIPSCs ( 0.25 vs 0.11 ; Fig. 10 , legend). Such larger percentage of singly bound states in mIPSCs results from a shorter exposure of receptors activated by "synaptic GABA application" (Fig. 10B,D,E, insets). Moreover, as shown in Figure 10, $E$ and $F$, in the case of "synaptic" time course of the agonist, CPZ affected the rise time kinetics to a much smaller extent when compared with currents evoked by brief agonist application. However, when modelling the synaptic current, assuming slower time constant of agonist decay $\tau$ (e.g., 200 or $300 \mu \mathrm{sec}$ ), the model would predict a stronger effect of CPZ on the mIPSC rise time (similar to the effect of CPZ on the rise time of current evoked by 1 msec GABA application, data not shown) contrary to experimental evidence.

Thus, our analysis provides evidence that the differences between the effect of CPZ on mIPSCs and on the evoked currents are mostly caused by a different time course of agonist concentration in the two situations.

\section{DISCUSSION}

The major finding of the present work is that CPZ, a widely used antipsychotic drug, strongly affects the GABA-mediated inhibitory synaptic transmission by decreasing the amplitude and by accelerating the decay of mIPSCs. We provide evidence that these effects are caused by CPZ-induced changes in the binding and unbinding kinetics of $\mathrm{GABA}_{\mathrm{A}}$ receptors. Interestingly, our data show that the effects of CPZ on mIPSCs could be obtained at micromolar concentrations similar to those attained in the brain of psychotic patients (May and Van Putten, 1978).

A noncompetitive block of $\mathrm{GABA}_{\mathrm{A}}$ receptors by $\mathrm{CPZ}$ has been proposed by Zorumski and Yang (1988). The $\mathrm{EC}_{50}$ for $\mathrm{CPZ}$ reported by these authors $(2.6 \mathrm{~mm})$ was much larger than that obtained in our experiments even when using slower multibarrel perfusion system $\left(30 \%\right.$ of block by $100 \mu \mathrm{M}$ CPZ indicates $\mathrm{EC}_{50}$ $\sim 230 \mu \mathrm{M})$. The source of this discrepancy is not clear. The limited speed of drug application used by Zorumski et al. (1988) (as in the case of the multibarrel system) did not allow to elucidate the mechanisms of CPZ action. By using the fast perfusion system, we were able to observe the effects of $\mathrm{CPZ}$ with a much better time resolution, making it possible to get an insight into the mechanisms underlying the effects of CPZ. The modification of the kinetics of the mIPSCs was clearly of postsynaptic origin because this drug had a similar effect on the responses evoked by fast GABA applications to outside-out patches. The present data as well as the model simulations indicate that the decrease in the binding rate $k_{\text {on }}$ and the increase in the unbinding rate $k_{\text {off }}$ are sufficient to reproduce qualitatively the postsynaptic effects of
CPZ on mIPSCs. In particular, the postulated decrease in $k_{\text {on }}$ by $\mathrm{CPZ}$ would slow agonist binding, making this process rate limiting for channel activation. Consequently, in conditions of very short exposure of $\mathrm{GABA}_{\mathrm{A}}$ Rs to GABA (especially in the case of mIPSC), a lower percentage of receptors would get bound and reach the open state. Strong acceleration of mIPSC decay kinetics is attributed mainly to CPZ-induced increase in the unbinding rate $k_{\text {off }}$. According to the model (Fig. $8 A$ ), the increase in $k_{\text {off }}$ leads to a decrease in the probability of visiting the desensitized states (not affected by CPZ), shortening thus the deactivation process (Jones and Westbrook, 1995, 1997). Thus, it seems that the mIPSC inhibition by CPZ is not a consequence of a direct block of channel pore by the drug but rather results from an "upsetting" of kinetics of the receptor, probably caused by an allosteric modulation by CPZ. An occlusion of channel pore by CPZ, if present, seems to be negligible because the current amplitudes elicited by saturating GABA concentration in control conditions and in the presence of $\mathrm{CPZ}$ are not significantly different (Fig. 6E). In addition, the observed mIPSC inhibition by CPZ does not fulfill the criteria of a classical competitive block. In the case of such antagonism, the receptor before it is activated, must dissociate the blocker molecule. We could suppose that the CPZ-induced decrease in the onset rate of GABA responses reflects a delay caused by dissociation of the $\mathrm{CPZ}$ molecule from the GABA-binding site. However, in classical mechanism of competitive block, antagonist dissociation rate does not depend on the agonist concentration. Thus, the fact that the effect of CPZ on rise time kinetics can be compensated by increasing dose of GABA (Fig. 6 $A, B$ ) argues against any significant contribution of competitive antagonism to the observed mIPSC inhibition by CPZ.

In our simulations we used the model (Fig. $8 A$ ) previously proposed by Jones and Westbrook (1995). However, as described in Results, the values of the rate constants were changed to obtain a better fit to our experimental data. The most apparent was the difference between the rate constants determining the rising kinetics $\left(k_{\mathrm{on}}, \beta_{2}\right)$ reflecting faster current onset in our experiments. In the study of Jones and Westbrook (1995) (see Fig. 2A), the rise time of the responses to 1 and $3 \mathrm{~mm}$ GABA were 3-4 msec and 1-2 msec, respectively, whereas in our experiments these values were $1.12 \mathrm{msec}$ and $0.76 \mathrm{msec}$. This discrepancy may reflect different receptor kinetics in the two preparations and possibly a difference in speed of agonist application.

An interesting prediction of our model is that the effect of $\mathrm{CPZ}$ on mIPSCs and on currents evoked by brief GABA applications is associated with an increased proportion of monoliganded open states during current activation. This is a consequence of a slower activation kinetics while the agonist application remains short. As described in Results, the model simulations indicate that such increased proportion of monoliganded open states accelerates the deactivation kinetics because of a low probability of entering the singly bound desensitized state (AD). In our experiments, we have observed that $\mathrm{CPZ}$ affects the mIPSC decaying phase to a larger extent than that of the evoked currents [30 $\mu \mathrm{M} \mathrm{CPZ}$ caused a strong acceleration of mIPSC decay (Fig. 1), whereas its effect on GABA-evoked currents was negligible (Table 2)]. A possible explanation of this difference could be a larger proportion of monoliganded open states during activation of mIPSC caused by much shorter receptor exposure to agonist in the case of the synaptic current. 


\section{CPZ effect reveals fast GABA clearance during mIPSC}

The analysis of the effect of CPZ on mIPSCs and on evoked currents provides evidence that the agonist clearance is very fast $(\sim 100 \mu \mathrm{sec})$. The key indication was the concomitant observation of a stronger $\mathrm{CPZ}$ effect on amplitude and smaller effect on the rising rate of mIPSC with respect to the currents evoked by brief GABA pulses. This indicates that during mIPSC, the presence of GABA is so short that in the case of slower receptor activation (caused by CPZ) less receptors activate, but still no effect is seen on the mIPSC onset. The above indications are nicely confirmed by the model simulations showing that for slower $\tau$ values of GABA clearance, the effect of CPZ on mIPSCs should be associated with a decrease in mIPSC rising rate (not observed in experiments). Thus, the effect of CPZ provides a tool to reveal kinetics of agonist clearance during GABAergic synaptic transmission.

\section{Physiological implications from modelling mIPSCs}

Although the fast perfusion system is an excellent and, so far, unique tool to mimic the synaptic events, the comparison of responses evoked using this technique to the synaptic ones should be done with caution. The main reason for possible discrepancies is that the synaptic agonist time course is still faster than that obtained with fast perfusion. For instance, we suggest that the differences in the effect of CPZ on mIPSCs and on evoked currents are consequences of faster agonist clearance during mIPSC.

Our data indicate that the peak GABA concentration in the synaptic cleft is at least $3 \mathrm{~mm}$. This is supported by the observations that the rise time of currents evoked by fast GABA applications saturates at $\sim 3 \mathrm{~mm}$ and that this maximum rising rate is very similar to that of mIPSCs (Table 1, Fig. 3). However, this peak value of [GABA] differs substantially from those reported previously (Maconochie et al., 1994, 500-1000 $\mu \mathrm{M}$; Jones and Wesbrook 1995, $527 \mu \mathrm{M}$ ). This discrepancy most likely reflects differences in the activation rates of GABA responses. Maconochie et al. (1994) have observed that the on rate of the evoked currents reaches saturation already at $[\mathrm{GABA}]=1 \mathrm{~mm}$, whereas in our experiments at $[\mathrm{GABA}]=3 \mathrm{~mm}$. Jones and Westbrook (1995), reported the IPSC rise time of $\sim 3 \mathrm{msec}$ (rate of rise, $347 \mathrm{sec}^{-1}$ ) whereas in our experiments the time-to-peak was $0.68 \pm 0.09 \mathrm{msec}$. It needs to be emphasized, however, that also in a number of other studies a submillisecond rise time of IPSC was reported (Edwards et al., 1990; Maconochie et al., 1994; Bier et al., 1996; Mellor and Randall, 1998; Williams et al., 1998).

It seems interesting how sensitive the response of the postsynaptic receptors is to different patterns of agonist time course investigated in the present work. The effective exposure $E$ (see Materials and Methods) for the simulation of synaptic current ( $A=3 \mathrm{~mm}, \tau=100 \mu \mathrm{sec}$ ) is 10 times smaller than that for the square-like GABA pulse ( $3 \mathrm{~mm}$ for $1 \mathrm{msec}$ ) being 0.3 and 3 $\mathrm{mm} / \mathrm{msec}$, respectively. However, the charge transfer caused by the mIPSC is only slightly smaller $(<5 \%)$ than that evoked by square GABA pulse. This suggests that receptors, bearing the properties predicted by our model, are particularly suitable to efficiently respond to agonist applications characterized by high peak concentration and very fast time course. Consequently, such receptors would assure a good performance of synaptic transmission. It is known that high peak agonist concentration is caused by a very small volume of the synaptic cleft, and that the fast time course is mainly caused by diffusion, that at such small distances is an extremely fast process (Hille, 1992). Thus, once released, the agonist time course must be very fast because its kinetics is determined by a spontaneous trend toward thermodynamic equilibrium. One can speculate that to assure an optimal performance of synaptic transmission, it was easier to "adopt" the receptor properties to the time course of agonist than vice versa. Consequently, such receptor properties may reflect a perfection of cooperation between agonist release and receptor activation kinetics in the synapse.

In conclusion, our results suggest that the agonist time course in the synaptic cleft is crucial not only for the kinetics of the synaptic currents but also for their modulation by pharmacological agents. A striking discrepancy between the effect of $\mathrm{CPZ}$ on mIPSCs and on the whole-cell GABA-evoked responses provides a clear example how large the impact of differences can be in nonequilibrium conditions underlying receptor activation. One of the practical implications of these findings is that the formalism based on the equilibrium Hill equation, widely used to describe the dose-response relationships, should be used with caution when describing the effects of various factors on synaptic currents. The reason for this is that this equation is based on the assumption that the system is in the equilibrium whereas, as already discussed, the synaptic transmission consists of a sequence of highly nonstationary processes.

\section{REFERENCES}

Agopyan N, Krnjevic K (1993) Effects of trifluoperazine on synaptically evoked potentials and membrane properties of CA1 pyramidal neurons of rat hippocampus in situ and in vitro. Synapse 13:10-19.

Andjus PR, Stevic-Marinkovic Z, Cherubini E (1997) Immunoglobulins from motoneurone disease patients enhance glutamate release from rat hippocampal neurones in culture. J Physiol (Lond) 504:103-112.

Benoit P, Changeux JP (1993) Voltage dependencies of the effects of chlorpromazine on the nicotinic receptor channel from mouse muscle cell line So18. Neurosci Lett 160:81-84.

Bier M, Kits KS, Borst JGG (1996) Relation between rise times and amplitudes of GABAergic postsynaptic currents. J Neurophysiol 75:1008-1012.

Bolotina V, Courtney KR, Khodorov B (1992) Gate-dependent blockade of sodium channels: structure-activity relationships. Mol Pharmacol 42:423-431.

Changeux JP, Pinset C, Ribera AB (1986) Effect of chlorpromazine and phencyclidine on mouse C2 acetylcholine kinetics. J Physiol (Lond) 378:497-513.

Clements JD (1996) Transmitter time course in the synaptic cleft: its role in central synaptic function. Trends Neurosci 19:163-170.

Dinan TG, Crunelli V, Kelly JS (1987) Neuroleptics decrease calciumactivated potassium conductance in hippocampal pyramidal cells. Brain Res 407:159-162.

Edwards FA, Konnerth A, Sakmann B (1990) Quantal analysis of inhibitory synaptic transmission in the dentate gyrus of rat hippocampal slices: a patch-clamp study. J Physiol (Lond) 430:213-249.

Gould RJ, Murphy MM, Reynolds IJ, Snyder (1983) Antipsychotic drugs of the diphenylbutylpiperadine type act as calcium channel antagonists. Proc Natl Acad Sci USA 80:5122-5125.

Hille B (1992) Ionic channels of excitable membranes. Sunderland, MA: Sinauer.

Itil TM, Soldatos C (1980) Epileptic effects of psychotropic drugs. J Am Med Assoc 244:1460-1463.

Jonas P (1995) Application of agonists to isolated membrane patches. In: Single channel recordings (Sakmann B, Neher E, eds), pp 231-242. New York: Plenum.

Jones MV, Westbrook GL (1995) Desensitized states prolong GABA channel responses to brief agonist pulses. Neuron 15:181-191.

Jones MV, Westbrook GL (1996) The impact of receptor desensitization on fast synaptic transmission. Trends Neurosci 19:96-101.

Jones MV, Westbrook GL (1997) Shaping of IPSCs by endogenous calcineurin activity. J Neurosci 17:7626-7633.

Lidsky TI, Yablonsky Alter E, Zuck LG, Banerjee SP (1997) Antipsychotic drug effects on glutamatergic activity. Brain Res 764:46-52. 
Maconochie DJ, Zempel JM, Steinbach JH (1994) How quickly can $\mathrm{GABA}_{\mathrm{A}}$ receptors open? Neuron 12:61-71.

May PRA, Van Putten T (1978) Plasma levels of chlorpromazine in schizophrenia. Arch Gen Psychiatry 35:1081-1087.

Mellor JR, Randall AD (1998) Voltage-dependent deactivation and desensitization of GABA responses in cultured murine cerebellar granule cells. J Physiol (Lond) 506:377-390.

Mody I, De Konnick Y, Otis TS, Soltesz I (1994) Bridging the cleft at GABA synapses in the brain. Trends Neurosci 17:517-525.

Müller M, De Weille JR, Lazdunski M (1991) Chlorpromazine and related phenothiazines inhibit the ATP-sensitive $\mathrm{K}^{+}$channel. Eur J Pharmacol 198:101-104.

Ogata N, Nishimura M, Narahashi T (1989) Kinetics of chlorpromazine block of sodium channels in single guinea-pig cardiac myocytes. J Pharmacol Exp Ther 243:605-613.

Pearce RA (1993) Physiological evidence for two distinct GABA $_{\mathrm{A}}$ responses in rat hippocampus. Neuron 10:189-200.

Peroutka SJ, Snyder SH (1980) Relationship of neuroleptic drug effects at brain dopamine, serotonin, $\alpha$-adrenergic, and histamine receptors to clinical potency. Am J Psychiatry 137:1518-1522.

Puia G, Costa E, Vicini S (1994) Functional diversity of $\mathrm{GABA}_{\mathrm{A}^{-}}$ activated $\mathrm{Cl}^{-}$currents in Purkinje versus granule neurons in rat cerebellar slices. Neuron 12:117-126.

Sand O, Sletholt K, Gautuik K, Haug E (1983) Trifluoperazine blocks calcium dependent action potentials and inhibit hormone release from rat pituitary tumour cells. Eur J Pharmacol 86:177-184.

Seeman P (1980) Brain dopamine receptors. Pharmacol Rev 32:229-313.

Silver RA, Colquhoun D, Cull-Candy SG, Edmonds B (1996) Deactivation and desensitization of non-NMDA receptors in patches and the time course of EPSCs in rat cerebellar granule cells. J Physiol (Lond) 493:167-173.

Snyder SH, Banerjee SP, Yamamura SP, Greenberg D (1974) Drugs, neurotransmitters and schizophrenia. Science 184:1243-1253.

Toone BK, Fenton GW (1977) Epileptic seizures induced by psychotropic drugs. Psychol Med 7:265-270.

Williams SR, Buhl EH, Mody I (1998) The dynamics of synchronised neurotransmitter release determined from compound spontaneous IP$\mathrm{SCs}$ in rat dentate granule neurones in vitro. J Physiol (Lond) 510:477-497.

Zorumski CF, Yang J (1988) Non-competitive inhibition of GABA currents by phenothiazines in cultured chick spinal cord and rat hippocampal neurons. Neurosci Lett 92:86-91. 